Margo Bargheer

\title{
Quality Control and Evaluation of Scientific Web Resources
}

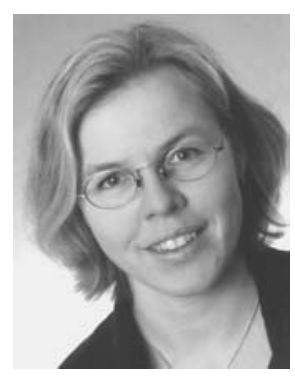

Scientific information in the Internet has become crucial for the scientific work. Libraries which operate scientific information services such as Quality Controlled Subject Gateways (QCSG), portals or virtual libraries therefore need to evaluate the quality of scientific resources in order to index them. The following article encloses media-theoretical thoughts on the scientific information space within the new medium Internet and its implications for the contained media products as well as an overview on evaluation approaches. Additionally the article offers practical help such as detailed quality criteria and an analysis of the evaluation process. The practical help is given in a way that allows (subject-) specific adaptation.

Qualitätskriterien und Evaluierungswege für wissenschaftliche Internetressourcen

Wissenschaftliche Informationen im Internet gewinnen zunehmend an Bedeutung. Um sie als zuverlässige Ressourcen für die wissenschaftliche Arbeit zu erschließen, müssen sie auf ihre Qualität geprüft werden-eine Aufgabe, die vermehrt von wissenschaftlichen Bibliotheken über ihre Internetdienste wie Subject Gateways, Digitale oder Virtuelle Bibliotheken wahrgenommen wird. Der vorliegende Artikel bietet eine medientheoretische Diskussion zum wissenschaftlichen Informationsraum im Internet und den medienbedingten Auswirkungen auf die Inhalte sowie einen Überblick zur Entwicklung von Evaluationsansätzen für Internetressourcen. Die theoretischen Abhandlungen werden durch einen umfangreichen Serviceteil ergänzt, der detailliert Qualitätskriterien und den Evaluierungsprozess in einer Weise aufzeigt, welche die Anpassung an (fach-) spezifische Anforderungen ermöglicht.

Critères de qualité et évaluation des ressources scientifiques de l'Internet

L'information scientifique dans l'Internet est devenue importante pour le travail scientifique. C'est pour cette raison que les bibliothèques qui offrent des services d'information scientifique tels que Quality Controlled Subject Gateways, portails et bibliothèques virtuelles doivent évaluer la qualité des ressources scientifiques afin de les indexer. L'article présent propose des idées média-théoriques concernant l'espace de l'information scientifique dans le nouveau médium Internet et concernant les implications pour les produits média inclus. L'article offre de même un aperçu sur plusieurs approches d'évaluation. En plus l'article propose des aides pratique comme des critères de qualité et une analyse du procès d'évaluation. L'aide pratique est présentée d'une manière qui permet des adaptations spécifiques à plusieurs sujets.

\section{Introduction}

This article is a shortened version of a detailed report delivered in German as part of the DFG'-funded project "Datenbankbasierte Clearinghouses im Kontext digitaler Bibliotheken" (DBClear) ${ }^{2}$. The project aimed at the development of content-regarding and technical concepts which could be reused by operators of Clearinghouses and Subject Gateways. The technical side focussed on the development of a JAVA-based working environment with automation and workflow components on top of relational databases. The report ${ }^{3}$ "Qualitätskriterien und Evaluierungswege für wissenschaftliche Internetressourcen" reviewed existing literature and online resources on evaluation and analysed evaluation criteria for scientific web sites as well as the evaluation process itself. The main objective of the report was to give practical help to operators of scientific web-services.

\section{Scientific information Online}

Since the use of the Internet as a scientific communication and publication media the discussion persists how and with what criteria scientific information on the web should be evaluated when the medium they circulate in is congested and lacking clear structures. Even for us as long-term operators of several subject gateways it is delicate to reach a single and lasting definition of "scientific sites" or "scientifically relevant sites" as these definitions keep depending on different parameters such as subjects, target groups or economic and infrastructure conditions. Still, we postulate that the situation can be analysed in a way that the formalised description of evaluation criteria and the evaluation process itself becomes possible and that such a formalisation can become the base for subject- and user-specific modifications. As "scientifically relevant" we understand such resources that meet the requirements of scientific work and the recognition within the scientific community. This article focuses on resources accessible via http-requests in the "world wide web" and on information services with quality-controlled, free-of-charge and (largely) independent supply of information that have been chosen intellectually, documented and described by standardised metadata.

The second half of the nineties saw the breakthrough of the internet as a major mass medium. Since then its technical capacities and content have exploded with the circulating and archived sites by now counting in billions. Hence the medium's complexity in-

Deutsche Forschungsgemeinschaft = German Research Foundation

2 Duration 2000-2002, <http://www.social-science-gesis.de/Forschung/ Informationstechnologie/DBClear.htm>.

3 Shttp://webdoc.sub.gwdg.de/ebook/aw/2003/bargheer/v10.pdf>. 
creases while its information efficiency for the users decreases ${ }^{4}$. At the same time the Internet houses more and more premium resources and has turned into a crucial medium for the scientific communication and information. In areas such as scientific journals or reference works the internet is expected to become the primary medium ${ }^{5}$. For the peer-to-peer communication within the scientific community it has brought already considerable acceleration. Nevertheless, German student' ${ }^{6}$ as well as academic's and professor's ${ }^{7}$ media competence for scientific online research still lacks behind as most of them prefer simple "googling". But although search engines like Google have reached impressive performance, semantic containment is only rudimentarily supported and ranking results do not rest on subject-specific expertise or scientific standards.

Technical solutions like improving the search algorithms therefore do not suffice. Particularly the scientific culture needs to conform to the conditions the new medium creates, may it be enhanced "computer literacy" among the users or the improvement of specific scientifically oriented web services.

In the given situation such web services have to meet two ways of processing scientifically relevant information: locating and controlling. Traditionally libraries select - according to specific criteria - and collect publications as well as grant access to them, no matter in which technical format publications exist. Hence the indexing of online resources lies within their responsibility as well ${ }^{8}$. In Germany - like in most other European countries - academic libraries have taken on this responsibility, usually in accordance to the German special subject fields programme within the nationwide document delivery system or as central subject libraries.

The need to index all relevant publications for specific subjects has led to the situation that quite a few special subject fields have been endorsed with the respective web service such as a subject gateway, portal or clearinghouse. The increasing development of German virtual libraries ${ }^{9}$ that offer a single subject specific user interface for the retrieval of physical media such as printed materials or CD's together with the according online resources is a logical continuation. The first German subject gateways with quality controlled content and standardised metadata have been the DFG-funded Geo Guide and Math Guide at the State and University Göttingen (SUB), which had been designed 1996 and went online $1997^{10}$. By now they have been complemented with three other guides and one virtual library ${ }^{11}$. According to the net character of the medium the indexing of online resources within co-operations and networks such as the European meta subject gateway Renardus ${ }^{12}$ or the Resource Discovery Network ${ }^{13}$ is advisable.

\section{Quality Controlled Subject Gateways}

To be able to meet the requirements of the scientific community online resources need to be quality-controlled, ideally they are high-quality and evaluated resources which have been indexed according to classifications and thesauri ${ }^{14}$. If the following criteria are met the term Quality controlled Subject Gateways (QCSG) applies for a web service:

\section{Quality controlled Subject gateways}

- contents meet the quality requirements of the scientific community, hence targeted users mainly belong to this groups

- defined criteria for quality control and evaluation

- detailed description with metadata according to international standards, that allow search and browse functionality

- systematisation of certain metadata with thesauri and (subject specific) classifications
- resource description or abstracts

- according to international technical standards to permit interoperability

The usual thematic focus of such web services calls for quality control from two perspectives: from the librarian as well as the subject specific scientific position thus offering access to selected resources stemming from a certain information space. Hence they rely on the intellectual retrieval, defined quality control, indexing, comprehensive description and systematisation by metadata as well as regular availability checks ${ }^{15}$. The DESIRE project ${ }^{16}$ already described them as "academic institution owned and maintained system that builds a publicly accessible catalogue of subject specialist internet resources by the application of a predefined set of quality selection criteria". QCSG usually mediate real-time access, while the resources physically stay at the providing server. Exceptions are mirrored sites or acquired resources which otherwise couldn't be reached sufficiently.

${ }^{4}$ See OCLC White Paper on the Information Habits of College Students; How Academic Librarians Can Influence Student's Web-Based Information Choices. 2002. <http://www2.oclc.org/oclc/pdf/printondemand/ informationhabits.pdf $><14.02 .03>$ ).

5 See for the German situation Beck, Klaus et al.: Die Zukunft des Internet. Internationale Delphi-Befragung zur Entwicklung der Online-Kommunikation. Konstanz 2000 and Karminski, Andreas: Hoffnungsträger der Wissenschaft. Umweltforschung und Wissenstransfer via Internet. <http://www.oekom.de/verlag/german/periodika/poe/pdf/poe_forum_ kommun.pdf $><14.02 .03>$, Keller, Alice: Elektronische Zeitschriften im Wandel: eine Delphi-Studie. Wiesbaden 2001.

${ }^{6}$ See STEFI-Report Klatt, Rüdiger et al.: Endbericht „Nutzung elektronischer wissenschaftlicher Informationen in der Hochschulausbildung“, 2001, <http://www.stefi.de/download/bericht2.pdf> <14.02.03>: 1999 only $5 \%$ of the students used subject-gateways for their online-searches.

See BMBF-Report. Nearly half of the German university staff was unsecure about the information found on the Internet, only a quarter of them used subject gateways or felt sufficiently qualified for searching online information. <http://www.dl-forum.de/Foren/Strategiekonzept/ ErsteErgebnisse1/ErsteErgebnisse2/TabellenWissenschaftler.pdf> $<14.02 .03>$.

${ }^{8}$ See Thomas, Christine: Bibliotheken in der Informationsgesellschaft - nationale Initiativen. <http://archiv.ub.uni-bielefeld.de/veranstaltungen/ 1998/bielefeld.kolloquium.4/0011.htm $><14.02 .03>$.

${ }^{9}<$ http://www.virtuellefachbibliothek.de/>

10 See for more details Fischer, Thomas / Neuroth, Heike: SSG-FI - special subject gateways to high quality Internet resources for scientific users. In: Online Information Review 24 (2000) 1.

11 The SUB runs five guides, Geo-Guide (<http://www.geo-guide.de $>$ ), Math Guide (<http://www.mathguide.de $>)$, Anglistik Guide $(<$ http: //www.anglistikguide $>$ ), History Guide (<http://www.historyguide $>$ ) and Forestry Guide (<http://www.forestryguide.de $>$ ) as well as the virtual library of Anglo-American culture (<http://www.sub.uni-goettingen.de/ vlib/>) Project information is available at <http://www.SUB.UniGoettingen.de/ssgfi/>).

$12<$ http://www.renardus.org $>$ is a European multilingual portal on the base of a common metadata system to allow search and browse over heterogeneous and distributed datasets of different providers.

$13<$ http://www.rdn.ac.uk/>.

14 See p. 11 in the recommendations of the German Scientific Board Wissenschaftsrat (WR): Empfehlung zur digitalen Informationsversorgung durch Wissenschaftliche Bibliotheken. <http://www.wissenschaftsrat.de/ texte/4935-01.pdf>, $2001<14.02 .03>$.

15 See Koch, Traugott: Quality-controlled subject gateways: definitions, typologies, empirical overview. In: Online Information Review 24 (2000) 1, p. 24.

16 DESIRE Projekt: Selection Criteria for Quality Controlled Information Gateways. 1998, <http://www.ukoln.ac.uk/metadata/desire/quality/ report-1.html $><14.02 .03>$. 


\section{Quality of Information}

In the context of web services quality needs to be viewed from two perspectives, on the one hand as a distinguishing feature that allows the identification of certain information such as "scientific" or "fictional", and on the other hand as a measure of value ${ }^{17}$. The former dimension refers to the librarian perspective, for example classifying a document according to formal criteria as a research paper. The latter perspective comes into play when such a research paper gets reviewed according to its scientific contents or argumentation. In the context of high-quality web services both dimensions keep depending on the users and their needs, as it is their participation that rounds out the information process ${ }^{18}$.

\section{Theory}

\section{Scientific Information Spaces}

"Science" can be considered as every intersubjectively verifiable analysis of facts, the according systematic description and - wherever possible - explanation. In reality science is carried out by mutually referenced agents through constant dispute and communication processes. Scientific communication traditionally happens within reference dialogs delayed through written communication, quality controlled through peer-reviews and intersubjectively verifiable ${ }^{19}$. The according communication processes mainly are put across by media and happen within a "scientific information space":

\section{The Scientific Information Space}

The physically and timely tangible as well virtual and ideational space, where scientific work and communication happens around certain topics. It consists of agents, institutions, discourses, theories and practices as well as artefacts of communication processes such as publications, visual and audio media or lectures and posters.

In the following we focus on the artefacts of communication processes. Generally this space is commonly supported by its agents and the conventions of the scientific work. Scientific agents usually draw on a precomprehension like certain formal and textual standards while producing scientific texts ${ }^{20}$ that shape those outcomes - be it formal criteria like the usual annotations in humanities, textual criteria like mentioning the main unit and sample size in quantitative studies or subject specific methods like the German juridical subsumption technique.

In the context of publishing printed or physical media such as CD's a certain culture exists that rests on a network of different scientifically oriented institutions such as renowned publishers, review bodies, subject bibliographies, national and subject specific libraries with their acquisitions lists ${ }^{21}$. This network generates a reliable information space for its participants who do not need to identify the contained information as scientific or non-scientific but only evaluate whether the found information is useful for them or not. Noteworthy for the "traditional" information space mainly referring to physically tangible media (print, $\mathrm{CD}$ etc.) are its principal communication strategies and economic conditions in this specific media environment. Scientific communication consists of three strategies with their respective medial form of expression and channels: information (messages and announcements), publication (display of research results in monographs or articles) and communication (in its narrow sense as discussion and verbal exchange). Scientific journals as a part of the scientific information space rest on the quality control through peer-review processes and the display of research results ${ }^{22}$. This leads to renowned author- ship as well as to the publicly available archive of the information space's artefacts. Who is able to publish what in which channel - to talk in Laswell's words - does not solely depend on the respective scientific competence of authors but is determined by science's integration into (and therefore dependency on) the market economy as well.

\section{Science on the Internet \\ - the Problem of Reliability in a new Medium}

New Boundaries in the Scientific Information Space

The Internet for the first time in the history of knowledge represents a world-wide, de-central communication medium without a controlling entity or clear objective. The traditional segregation of sender and receiver is blurring and everyone who is technically and economically able to participate can turn into a producer and publisher. In the chain of the information process previously discrete entities can be operated by single agents. Publishing is possible ad hoc without peer reviews, editors or inherent necessities such as print costs or rentability. Euphorically viewed the Internet could be a platform for the scientific discourse without geographic, political or economic exclusions - a free and boundless media environment!

Reality shows that besides cruft like pornography and extremism the uncontrolled publishing has severe detriments. Only fields where hardly any publishing activity beyond the academic fields exist manage to do without a quality control such as the pre-print server for theoretical physics operated by Paul Ginsparg.

Wherever information spaces are at risk to be corroded by ambitions and desires (political or economical) but generally require a certain quality of its contents quality-controlling bodies gain importance. Medical information on the Internet should be sound, up-to-date and safe. Hence several medical studies and metastudies $^{23}$ have analysed such online information. The cyber-physician Gunther Eysenbach stated in $2000^{24}$ that only $20 \%$ met these self-evident demands whereas the remaining had been outdated, incomplete, confusing or even harmful.

17 See Enderle, Wilfried, page 39: Der Historiker, die Spreu und der Weizen. In: Geschichte und Internet. Raumlose Orte-Geschichtslose Zeit. Zürich 2002. S. 49-63.

18 See Hobohm, Hans-Christoph: Qualität und Nutzerorientierung bei bibliothekarischen Internetprojekten - marketingstrategische Überlegungen zu den neuen Informationsdienstleistungen. p. 4 http://www.fhpotsdam.de/ hobohm/inetqual.pdf $>1998<14.02 .03>$.

19 See Hess-Lüttich, Ernest W.B.: Wissenschaftskommunikation und Textdesign. TRANS Nr. 6, September 1998. <http://www.inst.at/trans/ $6 \mathrm{Nr} /$ hess.htm $><14.02 .03>$.

${ }^{20}$ In our context the term ,text" refers to all mediated and reproducable scientific contents.

${ }^{21}$ See Enderle p. 38: Der Historiker, die Spreu und der Weizen. In: Geschichte und Internet. In Haber et al.: Geschichte und Internet. Zürich 2002.

22 Day, Michael: The scholarly journal in transition and the PubMed Central proposal, Ariadne Issue 21, September 1999. <http://www.ariadne.ac.uk/ issue 21/pubmed/ $><14.02 .03>$.

${ }^{23}$ See for example Griffiths, K. / Christensen, H.: Quality of web based information on treatment of depression: cross sectional survey. BMJ 2000; 321: 1511-1515 <http://bmj.com/cgi/content/full/321/7275/1511> $<14.02 .03>$ or Gagliardi, A. / Jadad, A.: Examination of instruments used to rate quality of health information on the internet:. BMJ 2002; 324 : $569-573<$ http://bmj.com/cgi/content/full/324/7337/569><14.02.03>.

${ }^{24}$ European Health Forum Gastein (EHFG) 2000, press information: Die Entwicklung von Qualitätskriterien für Web Sites. 27.-30. Sept. 2000 in Gastein. <http://www.ehfg.org/presscenter/2000/Forum/ qualityinfoonweb_d.htm $><14.02 .03>$. 
If a quality-control is missing fundamental features of the scientific communication get lost that the traditional media environment brought with it such as the common quotation and referencing practice, the quality-control exercised by peer-reviews and its intersubjective traceability. This altogether ensures on the one hand a certain independence of scientific insights ${ }^{25}$, on the other hand an environment where only scientific information can persist albeit their respective intertextual quality.

It is noteworthy that scientific web services who exert quality-control take up two lines of action which traditionally have been split between scientific publishers, subject bibliographies and libraries $^{26}$ : the (identifying) quality-control and the localisation of resources ${ }^{27}$. In the Internet the familiar segregating entities between producers and users are shifting as formerly separate entities like author, editor or publisher merge into one and in other cases new players join, for example students who publish new editions of their favourite authors.

Now new options arise, i.e. putting behind constant monetary shortcomings of scientific publishing, enlarging the participants of scientific communities, enhancing the scientific communication or allowing the world-wide literature and source studies from one's own desk.

On the other hand a reliable information space remains to be a valuable good. Would it be a solution to treat the online scientific information space like the academically institutionalised information spaces and solely consider such resources analogous to traditional media and their control mechanisms? This simplification would unnecessarily constrain the number of indexable resources. To cope with the new publishing situation within the Internet scientific web services like QCSG, Digital or Virtual Libraries need to have quality-control structures that in principal allow every scientifically relevant resource to be considered - no matter whether the publishing entity is renowned or not. The actual decision to index or reject a resource should rest on the features of the resource itself.

\section{Media-induced Changes of Content}

There are fundamental differences between resources in the traditional media environment and the Internet which influence more than just the output format. A bibliography for example refers to different books somewhere existing in time and space, indexed by catalogues and maybe available in a reading room. These entities are connected through the social processes of the media use, but due to their physical existence are able to stand for themselves. Whereas in the Internet there are no exact boundaries between content entities, retrieval or access as all of them consist of continuous electronic data processing whose existence in time and space does not have a fixed relation to its media products.

Moreover this process pertains to be vulnerable to technical problems or human manipulation and its durability and preservation from the librarian's point of view has not yet been solved satisfiable.

\section{a) Online Resources as Dynamically Generated Copies}

In the context of mass media the single media product as a physically tangible entity is a duplication. Its individual provenance or distribution outside the bibliophile area is of little interest as the conformity between the respective copy and the master usually can be assumed. Once indexed and acquired a book will not change regarding size or content.

Whereas online resources (except mirrored pages or factual copies) in fact are originals accessed virtually and manifold through presentation tools such as a browser instead of single duplications.
The copy is generated during the online access and therefore stays in a process stage. This dynamic character (Chapman et al..$^{28}$ regard them as "moving targets") calls for the special consideration of the resources' provenance and accessibility which stays intertwined with the media product itself. Furthermore Internet resource's contents technically depend on the providing infrastructure (reliable server) which therefore needs to be evaluated as well.

\section{b) Information and Information Carrier as Inseparably and Com- plementary}

The sequential access to information contained in written text is determining in a way that evaluating the information carrier usually can be neglected as technical and formal features of the media product "book" are secondary.

For digital resources information and information carrier constitute complementary aspects of a whole that grants access to its contents. Features like reliable navigation within the resource or content-adequate use of hypertextuality should be considered as well.

\section{c) Granularity, Complexity and Assigning Entities}

Determining entities, subsets or encompassing sets (granularity) for Internet resources stays problematic as there is no such starting point like " 2 boards +1 title $=1$ document $\Rightarrow 1$ metadata set". Endres and Fellner pragmatically defined a "digital document" as a digitally coded and self-contained information unit stored on an electronic data medium to be processed by computers. The term "digital object" thus addresses parts of such a document, e.g. an image or a directory ${ }^{29}$. But a "self-contained information unit" inevitably stays relative as the discrimination logic does not result from the media product itself. Resources can be fuzzy parts of encompassing systems but still form valuable resources in itself worthwhile indexing. Resources can exist as self-contained units but without an identification device such as an unambiguous title. To determine, name label and describe such resources means - strictly speaking - creating them.

In the digital world terms like "document", "object" or "resource" have to be assigned according to the context. Endres" and Fellner suggested to perceive documents as meaningful sets of digital objects whereas objects can be files of a certain format, such as a JPEG or a GIF. The American standardisation body NISO defined for libraries: "Documents can consist of several files or elements (text, image, multimedia), and be embedded in web frames. ${ }^{, 30} \mathrm{Ci}$ -

${ }^{25}$ See Hess-Lüttich, Ernest W.B.: Wissenschaftskommunikation und Textdesign. TRANS Nr. 6, September 1998. <http://www.inst.at/trans/ $6 \mathrm{Nr} / \mathrm{hess} . \mathrm{htm}><14.02 .03>$.

${ }^{26}$ Chapman, Anne / Day, Michael / Hiom, Debrah: Metadata - Cataloguing practice and Internet subject-based information gateways. Ariadne Issue 18, December 1998. <http://www.ariadne.ac.uk/issue18/metadata/> $<14.02 .03>$.

${ }^{27}$ Only by recognition publications become an active part of the scientific information space. Marketing strategies of the publishers are fundamental means for this as well as the admission into national and subject-specific bibliographies. see Enderle p. 38: Der Historiker, die Spreu und der Weizen. In: Geschichte und Internet. Zürich 2002.

${ }^{28}$ Chapman et al. <http://www.ariadne.ac.uk/issue18/metadata/> $<14.02 .03>$.

${ }^{29}$ See Endres, Albert / Fellner, Dieter W.: Digitale Bibliotheken - Informatik-Lösungen für globale Wissensmärkte. Heidelberg 2000.

${ }^{30}$ NISO Z.39 7 - 2002 Draft Version: Information Services and Use: Metrics \& statistics for libraries and information providers--Data Dictionary. Appendix B: Measuring the Use of Electronic Library Services. $<$ http: //www.niso.org/emetrics/current/appendixB.html $><14.02 .03>$. 
olek regarded documents as mosaics made up from single elements and resources as meaningful compilation of documents which could be part of collections like an archive ${ }^{31}$. Sowards ${ }^{32}$ differentiated resources according to layers, e.g. how many clicks it takes to reach the respective content-holding HTML pages. In the Göttingen Guides this conceptual discrimination has been taken up by the use of "web page", "web sub-site", and "website" as descriptive features for online resources (see fig. 1).

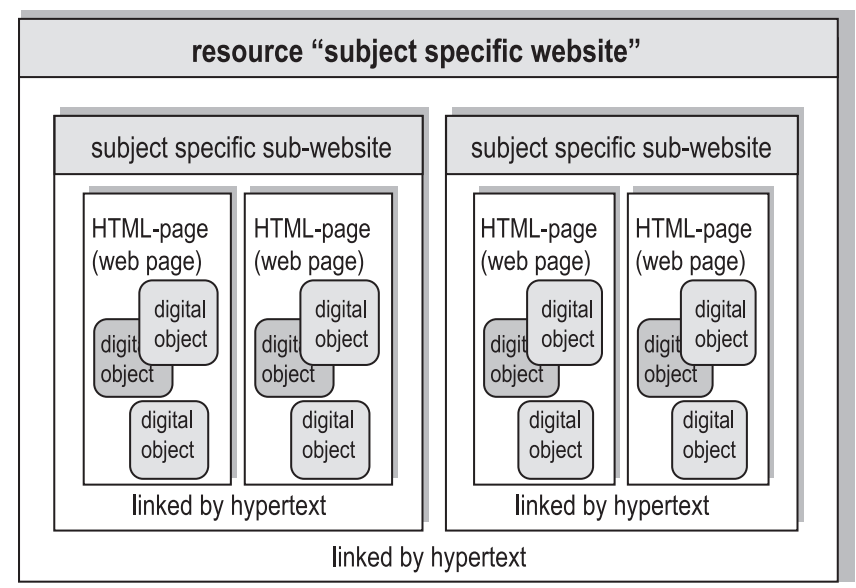

Fig. 1: Digital Objects, Documents and Websites

Subject-specific websites are defined as meaningful compilations of webpages accessible through a common start page. Therefore it is mainly sites instead of pages that get indexed in all of our guides.

The relative term "document" or "resource" results in new concepts of responsibility for the creators to clearly edit their products by placing meaningful titles, tags or abstracts. Furthermore the common "googling" might unload users somewhere in the middle of resources instead of the intended start page. Scientific resources therefore should carry a minimum internal labelling and facilitate meaningful resource description.

Printed materials pose certain upper limits regarding complexity, size or number of pages which call for the partition into series or multi-volume monographs. Online resources seem to be free of such limitations but still require an indexing starting point such as an URL, whether for a single HTML page or a highly complex resource like the RDN start page.

\section{d) Technical Requirements for Referencing}

The unambiguous identification of resources through devices like ISBN or ISSN pertains to be difficult as due to modification of the providing infrastructure contents may shift from their previous position of access. Besides reliable document repositories initiatives like URN ${ }^{33}$ (uniform resource name, operated by the Internet Engineering Task Force), $\mathrm{PURL}^{34}$ or $\mathrm{DOI}^{35}$, all based on the resolver concept as a virtual "mailbox" with a permanent address to keep track of changing physical access positions appear to be solutions. The assignment of such identifiers so far remains to be the task of the respective creators and is a formal quality criterion.

\section{e) Textual Requirements for Referencing}

The respective "duplication" of a resource is generated on the user's computer whose configuration influences the segmentation into single HTML pages without a reliable pagination. Scientific resources who do not require interactive or multimedia elements thus tend to be formatted as PDF. HTML-based resources gain in quality if they are parted into meaningful paragraphs or provide technical devices such as alphabetical indices or search engines to allow the verification of quotations and references.

\section{f) Original, Plagiarism or Fake}

The identification of respective original sources, copies, revised versions or even fakes stays difficult for internet resources especially when they are meant to serve as scientific references. Supplementary information such as time stamps, digital signatures or versioning details thus bring added value to resources which are meant to persist in the scientific information space.

\section{g) Internal Heterogeneity of Resources}

The new medium Internet has yielded new forms of media content and types. For example the formerly discrete discursive strategies "information", "publication" and "communication" within the scientific community for example by now can be found in single resources such as the social sciences gateways SOSIG (UK) or GESIS (Germany). Other resources are genuine multi-media products who's internal format relations (such as text/image connection) might need to be evaluated as well.

\section{h) Interoperability}

Besides its unchallenged merits the co-operation of scientific webservices poses certain difficulties. Respective terms for resource types often derive from traditional and local type assignments from the printed world which - through time consuming and sometimes inadequate mapping processes - need to be merged. The performance of a conjoint functionality such as an overall browsing structure thus is limited by the weakest contributing part.

\section{i) Responsibility for Documentalists}

From the documentalist's perspective internet resources call for a new sense of responsibility when regarding new forms of delivery and subscription, their complex legal structure concerning intellectual property rights or simply the need to archive the according hard- and software as well. An open question stays for example how documentalists regard changing holders of rights ${ }^{36}$.

\section{State-of-the-art: Evaluation of Resources in the Internet}

Evaluating scientific Internet resources usually follows some kind of formalised evaluation approach but at the same time rests on

31 The Six Quests for The Electronic Grail: Current Approaches to Information Quality in WWW Resources: <http://www.ciolek.com/PAPERS/sixquests1996.html $><08.05 .03>$.

32 Sowards, Steven W.: A Typology for Ready Reference Web Sites in Libraries. In: „First Monday 3 (1998) 5, <http://www.firstmonday.org/ issues/issue3_5/sowards/index.html $><14.02 .03>$.

33 To allocate unambigious and locally independent identifiers (URN) mostly seems to be a voluntary commitment of authors and creators. Publication servers like <http://pub.ub.uni-potsdam.de/urn.htm> from the University of Potsdam prescribe the allocation.

${ }^{34}$ Persistent Uniform Resource Locator as an initiative of OCLC, compatible with URN, <http://purl.oclc.org/>, in autumn 2002 there have been 568 000 PURLS.

35 Digital Object Identifier. <http://www.doi.org/> as a commercial service to protect intellectual property rights.

${ }^{36}$ See for the German situation p. $287 \mathrm{ff}$. in Tappenbeck, Inka: Metadaten für die Informationsversorgung von morgen. In: Rützel-Banz, M. (ed.): „Bibliotheken - Portale zum globalen Wissen“, 2001. Special edition Nr. 81, Zeitschrift für Bibliothekswesen und Bibliographie. 
common sense ${ }^{37}$, subject-specific expertise and practical experience. Therefore an exclusive way of correct evaluation does not exist. Nevertheless a useful evaluation approach should display the following features

- the distinctiveness of the medium and its effects on its products and contents are considered,

- the objectives and target groups for the evaluation are clear,

- a concept that refers to all main aspects of evaluation is there and fully covered,

- evaluation criteria follow this concept,

- evaluation is understood as a variable and context depending process,

- basic evaluation principles are laid down in a way to allow modification.

\section{User-oriented Approaches}

The need to evaluate Internet resources appeared after the euphoria on the new possibilities the Internet offered in the blues over the actual quality of web resources. McLure et al. ${ }^{38}$ stated four perspectives for quality and resulting evaluation approaches for Internet resources:

\begin{tabular}{|c|c|c|c|}
\hline 1. & 2. & 3. & 4. \\
\hline commercial & $\begin{array}{c}\text { information } \\
\text { technology }\end{array}$ & $\begin{array}{c}\text { information } \\
\text { and library } \\
\text { science }\end{array}$ & $\begin{array}{c}\text { media } \\
\text { pedagogic }\end{array}$ \\
\hline
\end{tabular}

From the commercial point of view quality is seen as a matter of popularity, attractiveness and rentability. Ciolek ${ }^{39}$ describes McKinley-Magellan with their Magellan Award and the Pointer Corporation as the first ones in this field from which the commercial award practice evolved.

The IT-perspective can be found in approaches for automatic evaluation. Ciolek for example saw a solution in operationalising values like "accuracy of the information" in order to quantify it and map it to a scale whereas Pitschmann ${ }^{40}$ regarded Harvester-Software as being able to check quality criteria according to strict guidelines, "but only experienced subject experts (i.e., bibliographers, content experts, scholars) possess the level of knowledge required to select high-quality resources". The dilemma addressed by the two authors resembles the one quantitative content analysis within the social science poses: to reach comparable results the measurement parameters have to be operationalised so tightly that only a small sector of the social reality is represented. Hence for the routine evaluation of heterogeneous resources these approaches are not sufficient.

\section{Librarian's Expertise for Evaluation}

When Internet resources became more obviously to be students' first choice in literature research librarians started to transfer their expertise regarding the quality of printed resources to the new medium. Especially the early approaches include a media-pedagogic demand to train the respective target group with a critical attitude towards the new information source Internet, for example "computer literacy for undergrads".

In many of the early evaluation guidelines two requirements for scientific information were prominently featured: contents should be verifiable and the creatorship trustworthy. Therefore many authors stressed the identification and evaluation of the author- and creatorship and the respective textual contents by using parameters like "objectivity" and "balance of arguments". The librarian Scott Brand ${ }^{41}$ for example presumed that "validity, reliability, and authenticity of information" should be evaluated and recommended to "check perspective by assessing biases presented in the infor- mation or its source". The discussion of the distinctive features of the new medium mainly referred to the media products itself, evaluation was mainly understood as a media-specific source critique. Another line of discussion regarded the handling of new techniques and formats that referred to media-specific aspects like access, indexing and navigation (for example in the often cited "Information Quality - Catalogue of Potent Truism"42).

\section{Interactive Evaluation}

Interactivity is a distinctive feature of the new medium Internet and is able to serve as a valuable evaluation device that for example allows quick and effective evaluation such as the "Information Quality Tool" for medical information ${ }^{43}$. With the help of a checklist users or indexers evaluate a given resource while the tool scales quality between 0 and $100 \%$ and contains three obligatory criteria: author/creator contact facilities, author/creator qualification, valid contents. The fact that the criterion "contact" is considered to be essential for medical information shows that evaluation tools need subject-specific adaptation. Information outside the medical sphere might still be regarded as high-quality even if the resource is anonymous.

Other interactive evaluation devices might serve as a tutorial for media-specific competence of source critique. The outstanding tutorial "Internet Detective" Skills" introduces users into the topic "online information quality" and guides through a detailed E-learning tour. The underlying evaluation concept rests on the DESIRE handbook and is organised according to the access logic by having the user first of all define his or her needs and relate them to the found resource, understand and classify the resource and finally evaluate the content. The tutorial proposes the following criteria for this process.

\begin{tabular}{|c|c|c|c|}
\hline „weighing up“ & $\begin{array}{l}\text { Content } \\
\text { Criteria }\end{array}$ & $\begin{array}{l}\text { Form } \\
\text { Criteria }\end{array}$ & Process Criteria \\
\hline$\Leftrightarrow$ & $\begin{array}{l}\text { Validity } \\
\text { Accuracy } \\
\text { Authority } \\
\text { Uniqueness } \\
\text { Complete- } \\
\text { ness } \\
\text { Coverage }\end{array}$ & $\begin{array}{l}\text { Navigation } \\
\text { User Support } \\
\text { Appropriate } \\
\text { Technologies }\end{array}$ & $\begin{array}{l}\text { Information } \\
\text { Integrity } \\
\text { Site Integrity } \\
\text { System Integrity }\end{array}$ \\
\hline
\end{tabular}

Another excellent example for the full use of the medium's potential to train Internet competence are the "Resource Discovery

${ }^{37}$ See Tillman, Hope: Evaluating Quality on the Net. März $2001<$ http: //www.hopetillman.com/findqual.html $><14.02 .03>$.

${ }^{38}$ McLure, Ch.. et al.: Quality Criteria for Evaluating Information Resources and Services Available from Federal Web Sites. In: Annual Review of OCLC Research 1997. <http://www.oclc.org/research/publications/arr/ $1997 /$ mcclure/mcclure_frameset.htm $>.<14.02 .03>$.

${ }^{39}$ Vgl. (Anm. 31).

${ }^{40}$ Pitschmann, Louis A.: Building Sustainable Collections of Free Third-Party Web Resources. June 2001, from the Council on Information and Library Resources. <http://www.clir.org/pubs/reports/pub98/ contents.html $><14.02 .03>$.

${ }^{41}$ Brandt, D. Scott: Evaluating Information on the Internet. <http:// thorplus.lib.purdue.edu/ techman/evaluate.htm $><14.02 .03>$.

${ }^{42}$ Ciolek, T. Matthew: Information Quality - Catalogue of Potent Truisms, revised version 1997. <http://www.ciolek.com/WWWVLPages/ QltyPages/QltyTruisms.html $><14.02 .03>$.

${ }^{43}<$ http://hitiweb.mitretek.org/iq/iqmain.asp $>$.

${ }^{44}$ The tour takes about 90 minutes, registration is obligatory: <http: //www.netskills.ac.uk/TonicNG/cgi/sesame?detective;>. 
Network Virtual Training Suites" which cover 46 different highereducation and scientific topics such as tourism, social science, physics or aviation by offering subject-specific tutorials. These courses train three aspects of competence,

a) information about the medium (what source types exist and how to recognise them, technical limits and potentials),

b) search and retrieval, especially for subject-specific information,

c) critical evaluation of found resources;

the respective "common pitfalls" show subject-specific problems of the Internet publishing. The Virtual Training Suites recommend to raise the following questions while checking an online resource:

\begin{tabular}{l|l} 
Who & contextualises and evaluates the creator \\
\hline Where & $\begin{array}{l}\text { asks for the physical location and the providing infrastruc- } \\
\text { ture and institution }\end{array}$ \\
\hline Why & evaluates the resource's objective \\
\hline When & evaluates the temporal validity \\
\hline What & relates the contents to user's information needs
\end{tabular}

\section{Evaluation approaches for libraries}

The evaluation concept that the librarian Alastair Smith ${ }^{45}$ introduced brought a distinct shift of perspective. Instead of providing support for the library user in the sense of a media-specific source critique Smith's text displayed a self-perception of scientific libraries as active players in the online scientific information space. Libraries now provided high-quality information services and their librarian's expertise to index scientific information on the Internet.

From this documentalist's and librarian's perspective other aspects than mainly the content quality of resources needs to be consid- ered. Smith thus introduced "scope" as the starting point for the evaluation which he recommended to break down into "What subject area, time period, formats or types of material are covered? Is the scope stated, e.g. through meta-information such as an introduction, or only implied? Does the actual scope of the resource match expectations?"

In his concept "scope" should be followed by the content's evaluation. The self-conception of libraries as providers for high-quality information is obvious when Smith states: "Sites can be useful both as information resources in themselves, and as links to other information. However users can be frustrated by lists of resources which look promising, but turn out to simply contain more links". Correspondingly he considered technical aspects with close relation to the content as well such as reliable access. Smith therefore has been cited already in the beginning of the DESIRE-project. The starting point into the documentalist' and librarian evaluation with "scope", "scope policy", "collection policy" or "selection policy" which Smith introduced can nowadays be regarded as a standard.

The DESIRE Information Gateway Handbook ${ }^{46}$ comprises a detailed documentation and manual of how to set up scientific webservices which rests on the different subprojects accomplished in DESIRE. The respective evaluation concepts for online resources are based on a common schema that differentiates the two activities "collecting" and "rating" during the evaluation. The check-up of scope and selection policy at the beginning refers to the collection aspect and is broken down into the user's needs and the collection's quality. Afterwards the evaluation examines the media product itself by checking the information content as well as formal and technical potentials. The "Quality Selection Criteria for Information Gateways" of the British Social Science Information Gateway (SOSIG) in the following table exemplify this procedure.

\begin{tabular}{l|l|l|}
\hline \hline Scope & criteria & aspects of the criteria \\
\multirow{2}{*}{$\begin{array}{l}\text { considering your users (needs of the } \\
\text { target group) }\end{array}$} & Information Coverage & scope, target group, source types \\
\cline { 2 - 2 } & Access Policy & regimentation of access, safety \\
\cline { 2 - 2 } & Cataloguing Policy & granularity, metadata system \\
\cline { 2 - 3 } & Geographical Coverage & provenance and language of resources \\
\cline { 2 - 3 }
\end{tabular}

\begin{tabular}{|l|l|l|}
\hline \hline Content & Validity & validity period, intersubjective verification \\
\hline \multirow{3}{*}{$\begin{array}{l}\text { evaluating the contained informa- } \\
\text { tion }\end{array}$} & Authority and Reputation of Source & authorship, peer review process, sponsors \\
\cline { 2 - 3 } & Accuracy & references, accuracy, spelling and grammar \\
\cline { 2 - 3 } & Comprehensiveness & coverage and depth \\
\cline { 2 - 3 } & Uniqueness & primary / secondary information \\
\cline { 2 - 3 } & Composition and Organisation & structure of the content \\
\cline { 2 - 3 } & Currency, Adequacy of Maintenance & \\
\cline { 2 - 2 }
\end{tabular}

\begin{tabular}{|l|l|l|}
\hline Form & Ease of Navigation & search and navigation functionality \\
\hline \multirow{2}{*}{$\begin{array}{l}\text { evaluating the medium (media } \\
\text { product quality of the resource) }\end{array}$} & Provision of User Support & FAQ, documentation, contact \\
\cline { 2 - 3 } & Use of recognised Standards & Metadata, W3C, standard MIME \\
\cline { 2 - 3 } & Appropriate use of Technology & adequate technology \\
\cline { 2 - 3 }
\end{tabular}

\begin{tabular}{l|l|l|}
\hline \hline Process & Information Integrity & evaluates the activity of the author / creator \\
\hline \multirow{2}{*}{$\begin{array}{l}\text { evaluating the system (performance } \\
\text { of the media product) }\end{array}$} & Site integrity & evaluates the activity of the webmaster \\
\cline { 2 - 2 } & System Integrity & evaluates the system administration \\
\cline { 2 - 2 }
\end{tabular}

45 Smith, Alastair: Criteria for evaluation of Internet Information Resources. 1997 <http://www.vuw.ac.nz/ agsmith/evaln/index.htm><14.02.03>.

$46<$ http://www.ukoln.ac.uk/metadata/desire/quality/report-1.html> $\leqslant 14.02 .03>$. 


\begin{tabular}{|l|l|l|}
\hline \hline collection management Policy & Collection Coverage and Balance & balance of the collection \\
\hline \multirow{2}{*}{$\begin{array}{l}\text { considering your service } \\
\text { (collection quality) }\end{array}$} & Availability of Internet Resources & significance of the collection within the Internet \\
\cline { 2 - 3 } & Availability of Library Resources & significance of the collection in relation to other (printed) material \\
\cline { 2 - 3 }
\end{tabular}

Quality Selection Criteria for Information Gateways from SOSIG (<http://www.sosig.ac.uk>)

In 2001 the librarian Louis Pitschmann ${ }^{47}$ has presented a detailed report on setting up durable collections of scientific online information. His evaluation concept resembles the one from DESIRE whereas his selection criteria have been broken down into context, content, form and user interface and technical aspects. Pitschmann has divided the aspect of content into the context (refers to authorship, reputation etc.) and the information content itself ${ }^{48}$.

According to Pitschmann these four aspects overlap and condition each other so that none of them is significant enough to solely evaluate a resource. Pitschmann sees their order less determined by their significance or meaning. ,Rather, they appear in an order that might facilitate the culling process."

\section{Reviews and Awards}

The concept of awards as an indicator for quality seems appealing as awards usually rest on third-party evaluation. In the Internet however very few awarding institutions lay open their criteria and even serious awards mainly refer to formal, technical or aesthetical criteria. If awards rest on criteria stemming from the same scientific space as the resources they intend to rate they can indeed be a useful certificate of quality. An example is the medical "Health on the Net" ${ }^{\prime \prime 9}$ web service which allows indexed sites to display the HON symbol. The Library of California follows the same principle that resources having been indexed by the "Librarian's Index to the Internet ${ }^{50 "}$ may display a graphic and thus their approved quality. Reviews usually are the work of experts who describe a resource in detail, relate it to the surrounding scientific information space and on this base appraise them. Whenever reviewing bodies belong to the approved scientific community and regard a given resource as scientific this is a direct indicator for quality. Such resources should be indexed. Examples for scientific reviewing bodies are the " $\mathrm{Col}-$ lege and Research Libraries News" ${ }^{51}$ and the journal "CHOICE" edited by the Association of College and Research Libraries. Due to the intense work and expertise they require, reviewing processes as a routine way of evaluation however are inappropriate. They can serve as a controlling entity within the scientific information space if they get recognised and approved within this space though. So far the Internet lacks institutionalised reviewing bodies although subject-specific discussion lists and new online journals fortunately seem to fill this gap. As an example the H-Net ${ }^{53}$ with its manifold lists should be mentioned.

\section{Summary of Evaluation Approaches}

The beginning of systematic evaluation of Internet resources can be traced down to the time when librarians started to give advice on how to use the new medium whereas libraries did not yet index those resources themselves. These media-pedagogic approaches have found their place in special tutorials as described before. As a reference work for the routine evaluation of Internet resources such training tools are less useful due to their didactic focus and their orientation towards the individual user's need whereas institutions have to index scientifically relevant resources that cover a broad spectrum of information needs.

A distinction between indexing and reviewing should be upheld within scientific web-services although a certain kind of rating evaluation underlies every indexing evaluation due to the following reasons:

a) only a very narrow scope allows the negligence of the actual contents, b) resource descriptions are a necessity for useful metadata but not every resource delivers one and

c) the heterogeneous character of resources might blur the target group of users.

Nevertheless it is the indexing evaluation that sets the framework for this rating undercurrent in order to grant access to a broad subject-specific spectrum within the Internet's scientific information space. Evaluation thus is limited to the simple decision whether a given resource is in principle a scientific one that reasonably complements the existing collection.

Therefore our focus lies on a librarian's point of view. Evaluation should begin with the collection's aspect (scope), regard the information's context, the actual content and finally appraise the formal and technical aspects of information access.

\section{Evaluation Criteria}

In the daily work evaluating scientific resources is a reflexive weighing between the information-providing institution's aims, the respective information objects and the information user's needs. Our experience shows that with rising routine the resource evaluation is a rather quick process determined by intuition and expertise and resting on a minimal programme of evaluation that decides whether to look into resources in more detail and index or reject them.

We see the individual formulation of a "scope" and "selection policy" as a prerequisite for operating a scientific web-service such as a subject gateway whereas a subject classification could form a useful guidance to decide which fields should be indexed with what intensity. The selection policy should also include which kind of resources (contents as well as source types and formats) are to be indexed. Political science services for example might index political sites without a scientific claim in order to provide source material for research.

The criteria for evaluating resources depend on their location within the scope as well as the respective resource type. We distinguish four levels of priority,

${ }^{47}$ See paragraph „Identification, Evaluation and Selection“ in: Building Sustainable Collections of Free Third-Party Web Resources. <http: //www.clir.org/pubs/reports/pub98/contents.html>.

${ }^{48}$ We have taken up Pitschmann's reasonable specification of context and content as argued in our following practical guidelines.

${ }^{49} \mathrm{HON}$ is a Swiss initiative: <http://www.hon.ch/Project/HON code.html>.

${ }^{50}<$ http://www.lii.org $>$.

${ }^{51}$ College and Research Libraries News (C\&RL NewsNet), Internet Reviews Archive, $<$ http://www.bowdoin.edu/ samato/IRA/> $<14.02 .03>$.

52 CHOICE. Current Reviews for Academic Libraries. <http://www.ala.org/ acrl/choice/index.html>.

53 Startpage of the H-Net: <http://www2.h-net.msu.edu/>. 


\begin{tabular}{|l|l|l|}
\hline & priority & how to use \\
\hline \hline 1 & obligatory & $\begin{array}{l}\text { has to be evaluated; if not met, source should } \\
\text { be rejected }\end{array}$ \\
\hline 2 & $\begin{array}{l}\text { strongly recom- } \\
\text { mended }\end{array}$ & $\begin{array}{l}\text { should be evaluated; doesn't have to be rea- } \\
\text { son for rejection }\end{array}$ \\
\hline 3 & recommended & can be evaluated, reliable indicator for quality \\
\hline 4 & $\begin{array}{l}\text { subordinate, con- } \\
\text { text depending }\end{array}$ & $\begin{array}{l}\text { could be evaluated; might be indirect indica- } \\
\text { tor for quality }\end{array}$ \\
\hline
\end{tabular}

whereas the logic of the evaluation process determines the order of the criteria. The content and its provenance for example is more important than the technical handling although in the daily routine criteria get hardly ever checked in a linear but mostly in a spiral

\begin{tabular}{|c|c|}
\hline \multicolumn{2}{|l|}{ Content Criteria } \\
\hline context of information & content, information content \\
\hline $\begin{array}{l}\text { creatorship } \\
\text { - responsibility for contents } \\
\text { - author } \\
\text { - editor } \\
\text { distribution } \\
\text { - publisher } \\
\text { - distributor } \\
\text { target group } \\
\text { relation to information space } \\
\text { - significance within the subject } \\
\text { - significance within the medium } \\
\text { - backlinks } \\
\text { - feedback }\end{array}$ & $\begin{array}{l}\text { content coherence } \\
\text { - validity }{ }^{54} \\
\text { - authority } \\
\text { - accuracy }{ }^{56} \\
\text { content coverage } \\
\text { - substantiveness } \\
\text { - comprehensiveness } \\
\text { - uniqueness (primary or secondary } \\
\text { information) } \\
\text { content form } \\
\text { - structure } \\
\text { - temporal validity } \\
\text { - description (metadata) }\end{array}$ \\
\hline
\end{tabular}

\begin{tabular}{|l|l|}
\hline \multicolumn{2}{|l|}{ Formal Criteria } \\
\hline form and presentation & technical features \\
\hline usability & usability \\
- layout / design / & - data formats \\
ergonomics of user interface & - metadata \\
- search / navigate / user support & - international standards \\
accessibility & accessibility \\
- barrier free Internet & - reliability \\
- reglementation of access & - safety \\
formal structure & interfaces \\
- data amount / data structure & - user and medium \\
- resource boundaries & - inter- and intramedial interfaces \\
- editorial details (about us) & \\
- metadata & \\
\hline
\end{tabular}

mode. The distinction between content and formal criteria has proven to be useful. Content criteria draw on the expert's knowledge whereas formal criteria would accord to a webmaster's or an administrator's requirements.

The quality criteria published by the Dutch web-service DutchESS might give further explanation to the ones mentioned above ${ }^{57}$.

\section{Content Criteria}

Contents do not stand for themselves but stem from a certain information context. Therefore the aspect "content" should be distinguished into the information's framework and the information itself. We understand context criteria as those regarding the surrounding scientific information space and those who actually shape the information itself.

\begin{tabular}{|c|c|c|c|c|}
\hline & Term & Description & Meaning and Significance & Priority \\
\hline & \multicolumn{4}{|l|}{ Creatorship } \\
\hline \multirow[t]{3}{*}{1.} & \multirow[t]{2}{*}{$\begin{array}{l}\text { responsibility } \\
\text { for contents } \\
\text { author } \\
\text { editor }\end{array}$} & $\begin{array}{l}\text { For the scientific information space the possibility to evaluate authorship is a crucial } \\
\text { quality criterion, like identifying or affirming someone responsible for the contents. } \\
\text { Resources which do not show their authors and how to contact them (just an e-mail } \\
\text { address might seem dubious for scientific resources) usually }{ }^{58} \text { get down-rated, pri- } \\
\text { mary information sources might even be rejected for this reason. }\end{array}$ & \multirow[t]{2}{*}{$\begin{array}{l}\text { trustworthy source, } \\
\text { quality of information }\end{array}$} & \multirow[t]{2}{*}{$1-2$} \\
\hline & & $\begin{array}{l}\text { - check biographic details, if in doubt validate by "whois"-queries about the domain } \\
\text { or search engines about other publications from the same source } \\
\text { - check if the authorship reveals an according scientific background }\end{array}$ & & \\
\hline & \multicolumn{4}{|l|}{ Distribution } \\
\hline 2. & publisher & $\begin{array}{l}\text { In the Internet author, editor or publisher often can not be clearly distinguished. } \\
\text { Unambiguous formats like e-journals can be evaluated with the traditional under- } \\
\text { standing of the publisher's role. An academic editing body might indicate quality } \\
\text { due to review-processes }\end{array}$ & $\begin{array}{l}\text { trustworthy source, } \\
\text { quality of information }\end{array}$ & $1-2$ \\
\hline \multirow[t]{2}{*}{3.} & distributor & $\begin{array}{l}\text { refers to the technical aspect of providing information, such as the operating body } \\
\text { for the server; the distributor should be evaluated in relation to source types; digitisa- } \\
\text { tion archives need more reliable technical infrastructure than conference announce- } \\
\text { ments for example }\end{array}$ & $\begin{array}{l}\text { quality of information regarding } \\
\text { access }\end{array}$ & 3 \\
\hline & & - URL analysis and "whois"-queries & & \\
\hline
\end{tabular}

${ }^{54}$ The term validity should be understood socio-scientifically, meaning, that an information is valid if it corresponds to the social reality that it ought to describe.

${ }_{55}$ Authority refers to the resource-intrinsic significance regarding the scientific relevance. Analytically authority therefore does not depend on the evaluation of a known author.

${ }^{56}$ Accuracy refers to the formal precision of information such as spelling and grammar or the provenance of tables and statistics.

$57<$ http://www.kb.nl/dutchess/manual/quality_eng.html\#int>.

${ }^{58}$ Institution sites often only name a webmaster. To identify an author for such sites can be disregarded as the institution usually is the creator of their web presence. 


\begin{tabular}{|c|c|c|c|c|}
\hline & Term & Description & Meaning and Significance & Priority \\
\hline & \multicolumn{4}{|l|}{ Target Group } \\
\hline 4. & target group & $\begin{array}{l}\text { does the (estimated) target group of the resource meets the scope of the information } \\
\text { service. Source types like institution homepages can neglect a target group, whereas } \\
\text { for primary information sites they should be considered (possible categories: popu- } \\
\text { lar, undergraduate, graduate, professional) }\end{array}$ & $\begin{array}{l}\text { quality of information } \\
\text { usability }\end{array}$ & 3 \\
\hline & \multicolumn{4}{|c|}{ Relation to Information Space } \\
\hline 5. & $\begin{array}{l}\text { subject } \\
\text { significance }\end{array}$ & $\begin{array}{l}\text { What else regarding the subject has the author published? What sources does she or } \\
\text { he refer to and are the references trustworthy and up-to-date? }\end{array}$ & significance of information & 4 \\
\hline \multirow[t]{2}{*}{6.} & \multirow[t]{2}{*}{$\begin{array}{l}\text { medium } \\
\text { significance }\end{array}$} & $\begin{array}{l}\text { what significance has the resource within the medium Internet? } \\
\text { Is the resource available in other media forms as well (printed, CD)? }\end{array}$ & \multirow[t]{2}{*}{ significance of information } & \multirow[t]{2}{*}{4} \\
\hline & & $\begin{array}{l}\text { - check similar online publications } \\
\text { - check links and references (do they mainly point to printed or online material?) } \\
\text { - check backlinks and associated sites from the same domain by "allinurl:URL" }\end{array}$ & & \\
\hline \multirow[t]{2}{*}{7.} & \multirow[t]{2}{*}{ backlinks } & $\begin{array}{l}\text { links who point to a given resource can be regarded as indirect quality criteria by } \\
\text { telling about distribution, influence and relevance of resources } \\
\text { Backlinks should be evaluated regarding qualitative aspects, their sheer amount has } \\
\text { little meaning } \\
\text { - geographic distribution } \\
\text { - reputation of the linking institution } \\
\text { - relation of backlinks and resource's period of time }\end{array}$ & \multirow[t]{2}{*}{$\begin{array}{l}\text { trustworthy source, quality of } \\
\text { information } \\
\text { significance of information }\end{array}$} & \multirow[t]{2}{*}{$3-4$} \\
\hline & & $\begin{array}{l}\text { - check backlinks on general search engines such as Google, Alltheweb, Altavista, } \\
\text { Inktomi by "link:URL" }\end{array}$ & & \\
\hline 8. & feedback & $\begin{array}{l}\text { resources should always offer the possibility to contact the author; by encouraging } \\
\text { feedback authors show that they are interested in improving their resources }\end{array}$ & quality of information & 4 \\
\hline
\end{tabular}

\section{Information Content of Resources}

Evaluating the actual information content should consider the respective source type as well because different source types result in different user's needs. Where information is generally scarce in the Internet quality requirements can be rather low, the further away resources are from the scope's centre or the higher their amount in certain fields and kinds is already the more they come under scrutiny. In order to distinguish in this way evaluation should differ from source type to source type. In the Göttingen Guides we have therefore distinguished five main groups that have been broken down subject-specifically, for example by complexity (collection, subject specific website, webpage), by format (image collection) or content (genre, time, space, names, disciplines):

a) Institutional Sites, Information Providers: Sites of institutions (virtual representations) such as academic institutes, university or state departments, museums, archives etc. b) Factual Reference Work: encyclopaedias, gazetteers, thesauri, ontologies. Such reference works do not necessarily refer to information and entities within but as well to those outside the Internet.

c) Information Sites, Bibliographic Sources: refers to structured compilations of secondary information such as subject-specific portals (virtual libraries, QCSG) or bibliographies, lists of journals, OPACs or abstract collections.

Information Sources, such as d) and e)

d) Thematic Sites: resources with an unambiguous subject; formally they might be a reference work or a mixture of primary and secondary information though,

e) Primary Information Sites: online resources that mainly provide first-hand information in digital form like essays, articles in journals, research information such as monographs, e-books etc.

\begin{tabular}{|c|c|c|c|c|}
\hline \multirow[t]{2}{*}{ a) } & \multicolumn{4}{|c|}{ source type: Institutional Sites, Information Provider } \\
\hline & Term & Description & Meaning and Significance & Priority \\
\hline & \multicolumn{4}{|c|}{ Content Coherence } \\
\hline & \multirow[t]{2}{*}{$\begin{array}{l}\text { validity } \\
\text { authority }\end{array}$} & $\begin{array}{l}\text { Is the resource "real", i.e. that what one would presume it would be under its title? Is } \\
\text { the institution's presentation their own official one or an authorised / independent / } \\
\text { polemic } \text { cersion? }^{59} \text { versions }\end{array}$ & \multirow[t]{2}{*}{ trustworthy source } & \multirow[t]{2}{*}{1} \\
\hline & & - check URL and editorial details & & \\
\hline & accuracy & $\begin{array}{l}\text { Inaccurate spelling, grammar or reference list, outdated links or incomplete informa- } \\
\text { tion suspect a missing review process. }\end{array}$ & quality of information & 2 \\
\hline & \multicolumn{4}{|c|}{ Content Coverage } \\
\hline & $\begin{array}{l}\text { substantive- } \\
\text { ness }\end{array}$ & Less important in this context & & \\
\hline & $\begin{array}{l}\text { comprehen- } \\
\text { siveness }\end{array}$ & $\begin{array}{l}\text { Requirements should be related to the scope; for scarce or hard-to-get information a } \\
\text { simple contact address might be already sufficient. }\end{array}$ & quality of information & $2-3$ \\
\hline & & - check whether the given page is indeed the start page (home, index) & & \\
\hline & uniqueness & Less important in this context & & \\
\hline & \multicolumn{4}{|l|}{ content form } \\
\hline & $\begin{array}{l}\text { information } \\
\text { structure }\end{array}$ & $\begin{array}{l}\text { Resources informing about institutions should offer easy access to relevant informa- } \\
\text { tion such as contact person, e-mail or address. }\end{array}$ & usability & 3 \\
\hline
\end{tabular}

${ }^{59}$ An example for a homepage that pretends to be the official representation: 
a) source type: Institutional Sites, Information Provider

\begin{tabular}{|l|l|l|l|l|}
\hline a) & source type: Institutional Sites, Information Provider & Meaning and Significance & Priority \\
\hline & Term & Description & $1-2$ \\
maintenance & $\begin{array}{l}\text { Check whether timely or durable is appropriate: } \\
\text { timely: time-sensitive information has to be up-to-date } \\
\text { durable } \text { information beyond up-to-dateness should ideally be archived }\end{array}$ & $\begin{array}{l}\text { quality of information } \\
\text { group / content description possible? }\end{array}$ & $\begin{array}{l}\text { quality of information } \\
\text { usability }\end{array}$ \\
\hline
\end{tabular}

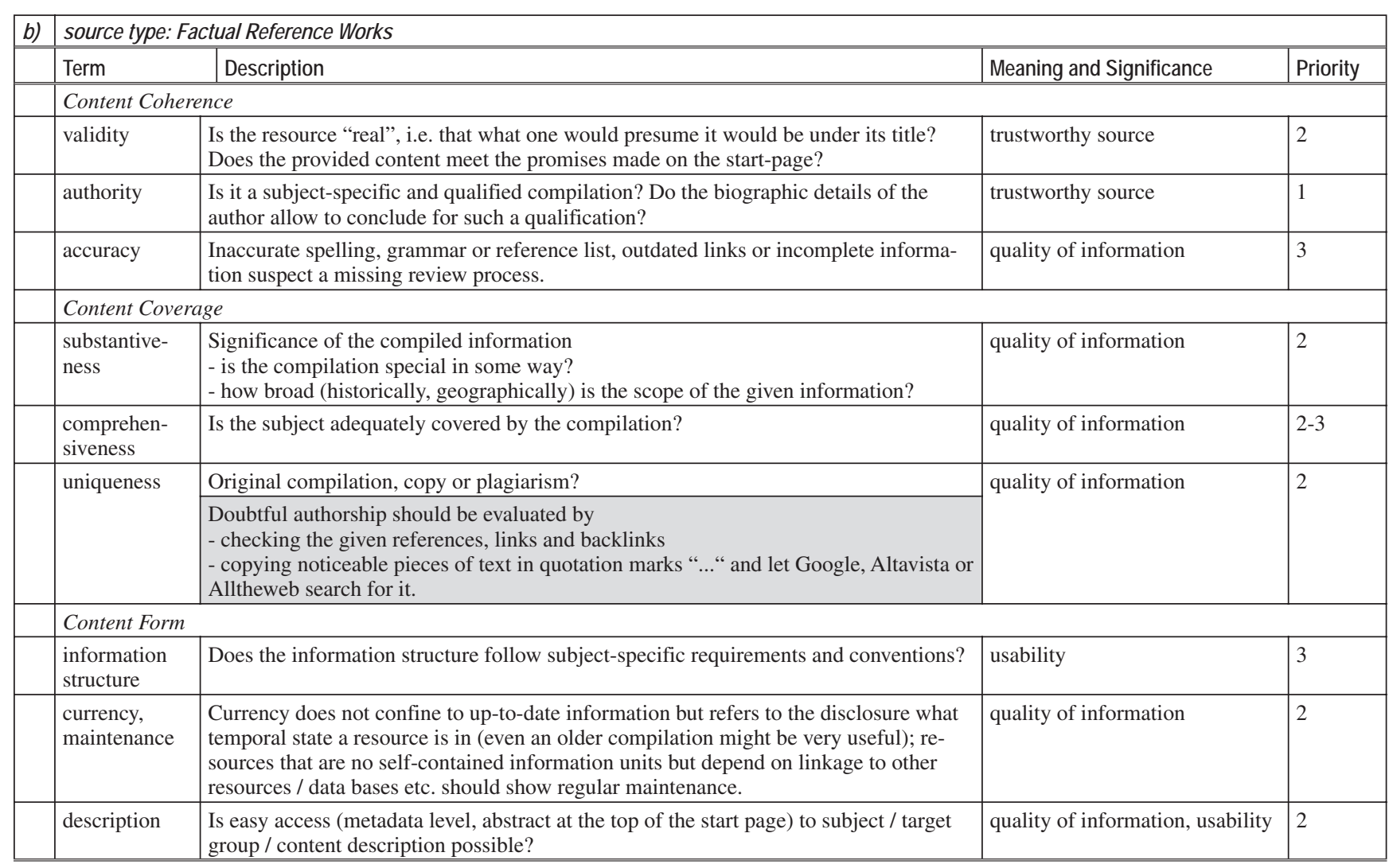

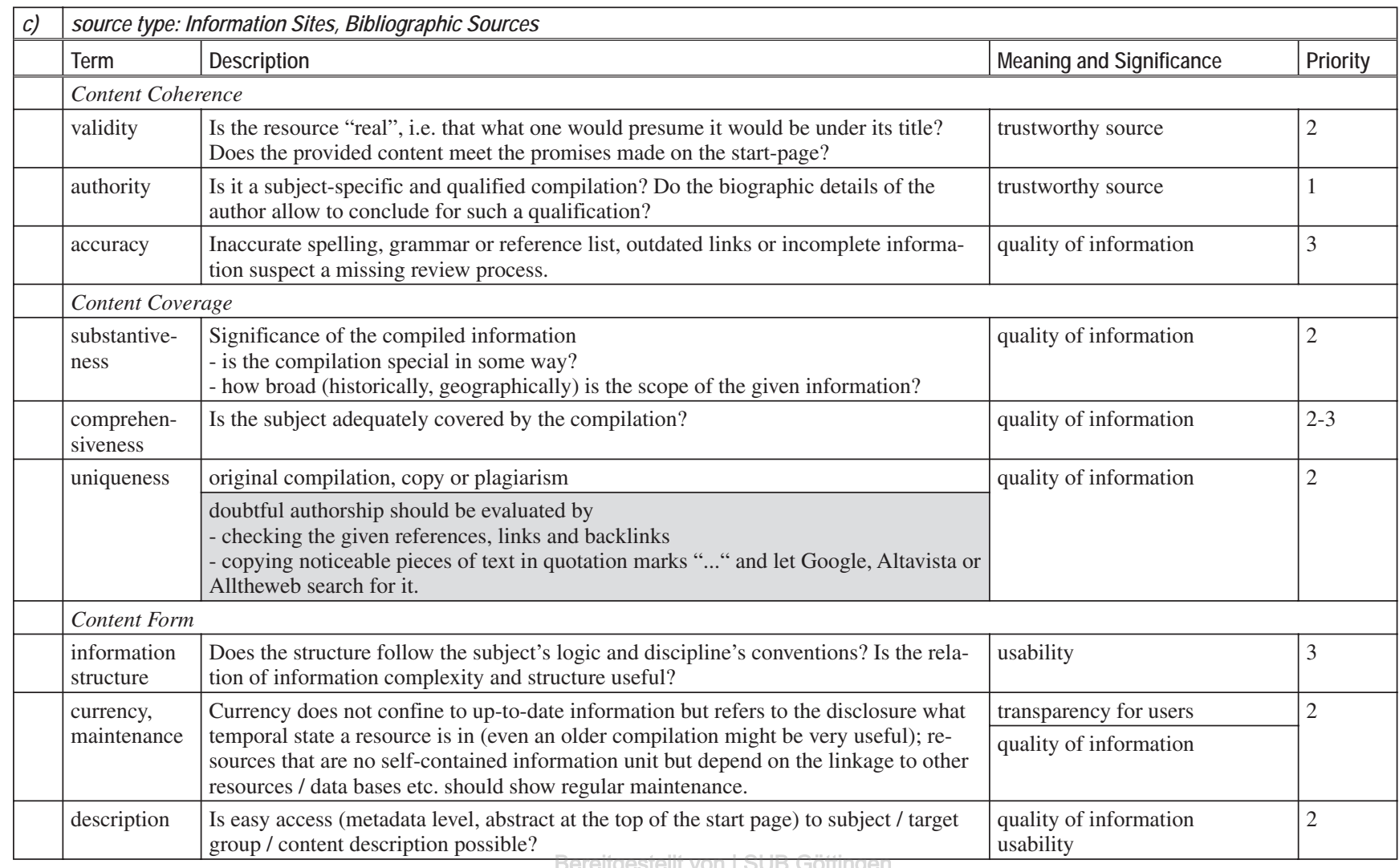




\begin{tabular}{|c|c|c|c|c|}
\hline \multirow[t]{2}{*}{$\begin{array}{l}\text { d) } \\
\text { e) }\end{array}$} & \multicolumn{4}{|c|}{$\begin{array}{l}\text { source type: Thematic Sites } \\
\text { Primary Information Sites }\end{array}$} \\
\hline & Term & Description & Meaning and Significance & Priority \\
\hline & \multicolumn{4}{|c|}{ Content Coherence } \\
\hline & validity & $\begin{array}{l}\text { - Is the resource "real", i.e. that what one would presume it would be under its title? } \\
\text { - how valid is the content, does it rest on scientific work (quotations, references, re- } \\
\text { view-process)? } \\
\text { - can you verify the content and the references / quotations? } \\
\text { - is there a reasonable relation of scientific point of view, bias and opinion - for exam- } \\
\text { ple presented as "scientific" but in fact polemic manipulations? }\end{array}$ & trustworthy source & 2 \\
\hline & authority & $\begin{array}{l}\text { What biographic details regarding the author does the resource give and do they sug- } \\
\text { gest competence? If the authority can not be evaluated (resource is anonymous, author } \\
\text { is mentioned but unknown) check the content more deeply. }\end{array}$ & trustworthy source & 2 \\
\hline & accuracy & $\begin{array}{l}\text { Inaccurate spelling, grammar or reference list, outdated links or incomplete informa- } \\
\text { tion suspect a missing review process. }\end{array}$ & quality of information & 3 \\
\hline & \multicolumn{4}{|c|}{ Content Coverage } \\
\hline & $\begin{array}{l}\text { substantive- } \\
\text { ness }\end{array}$ & $\begin{array}{l}\text { Thematic Sites: is there any insight gain beyond the compilation of second-hand } \\
\text { information and are there factual or primary contents? } \\
\text { Primary Information Sites: is it embedded into a theoretical context? Is it a critical } \\
\text { edition? Is the digital conversion described (what original, how converted)? }\end{array}$ & $\begin{array}{l}\text { trustworthy source, quality of } \\
\text { information }\end{array}$ & 3 \\
\hline & $\begin{array}{l}\text { comprehen- } \\
\text { siveness }\end{array}$ & $\begin{array}{l}\text { Does the provided content cover the subject of the resource? } \\
\text { Primary Information Sites: provided contents should ideally form a self-contained } \\
\text { information unit. }\end{array}$ & quality of information & 3 \\
\hline & uniqueness & Primary or secondary information? Does the resources relate to similar ones? & avoid repetition & 3 \\
\hline & \multicolumn{4}{|l|}{ Content Form } \\
\hline & $\begin{array}{l}\text { information } \\
\text { structure }\end{array}$ & $\begin{array}{l}\text { Is the information structured logically and graspable? } \rightarrow \text { important for tutorials and } \\
\text { other learning materials }\end{array}$ & usability & $2-3$ \\
\hline & \multirow[t]{2}{*}{$\begin{array}{l}\text { currency, } \\
\text { maintenance }\end{array}$} & $\begin{array}{l}\text { Currency does not confine to up-to-date information (unless this is the resource's } \\
\text { objective) but refers to the disclosure what temporal state a resource is in (even an } \\
\text { older thematic compilation might be very useful); resources that are no self-contained } \\
\text { information unit but depend on the linkage to other resources / data bases etc. should } \\
\text { show regular maintenance. }\end{array}$ & transparency for users & \multirow[t]{2}{*}{2} \\
\hline & & $\begin{array}{l}\text { Primary Information Sites: scientific resources have not yet been fully recognised as } \\
\text { quotable publications }{ }^{60} \text {. Currency and regular maintenance (server availability, ver- } \\
\text { sioning) ensure that Internet resources can be recognised as reliable, stable and thus } \\
\text { high-quality resources }\end{array}$ & quality of information & \\
\hline & description & $\begin{array}{l}\text { Is easy access (metadata level, abstract at the top of the start page) to subject / target } \\
\text { group / content description possible? }\end{array}$ & $\begin{array}{l}\text { quality of information } \\
\text { usability }\end{array}$ & 2 \\
\hline
\end{tabular}

\section{Formal Criteria}

Formal criteria refer to information mediation and its technology. They should be secondary to context and content as shortcomings of content aspects can not be balanced by formal features such as a flawless source code or a sophisticated user interface. If the content mediation however is disturbed due to formal or technical reasons resources should be down-rated or rejected.

\section{Form and Presentation}

Evaluating with the following means testing the resource's potential as a media product, i.e. if and how access is granted to the contained information. They comply to the aspect "form criteria" of the projects in DESIRE.

\begin{tabular}{|l|l|l|l|l|}
\hline & Term & Description & Meaning and Significance & Priority \\
\hline & Usability & $\begin{array}{l}\text { layout } \\
\text { design } \\
\text { ergonomics of } \\
\text { user interface }\end{array}$ & $\begin{array}{l}\text { layout and design should be evaluated according to their usability only although } \\
\text { aesthetic aspects should down-rate a resource if the visual appearance is irritating } \\
\text { or disturbing the information flow } \\
\text { - readability (language/complexity, typology, formatting, colouring and back- } \\
\text { grounds) } \\
\text { - adequate use of design elements such as graphics, images, effects, animation, } \\
\text { pop-up windows, frames } \\
\text { - ergonomic user interface } \\
\text { - continuity of visual / formal presentation, page-internal as well as regarding the } \\
\text { resource as a whole } \\
\text { - printer friendly? }\end{array}$ & $\begin{array}{l}\text { quality of information } \\
\text { usability }\end{array}$ \\
\hline
\end{tabular}

${ }^{60}$ Maurice Crouse recommends to cite electronic sources only, if they are available in no other way due to their ,invisible revisability“. In: Citing Electronic Information in History Papers. October $2002<\mathrm{http}$ : //cas.memphis.edu/ mcrouse/elcite.html $><14.02 .03>$. 


\begin{tabular}{|c|c|c|c|c|}
\hline & Term & Description & Meaning and Significance & Priority \\
\hline & \multicolumn{4}{|l|}{ Usability } \\
\hline 2. & $\begin{array}{l}\text { search func- } \\
\text { tionality }\end{array}$ & $\begin{array}{l}\text { should be evaluated in relation to the resource's complexity, conceptual quality is } \\
\text { indicated by: } \\
\text { - local search engines } \\
\text { - registers (alphabetical, numerical, geographical, etc.) for complex resources } \\
\text { - hitlists and result ranking } \\
\text { - semantic search help (keywords, index, synonyms etc.) }\end{array}$ & $\begin{array}{l}\text { usability } \\
\text { interoperability } \\
\text { quality of the service }\end{array}$ & $2-3$ \\
\hline 3. & $\begin{array}{l}\text { navigation } \\
\text { instruments }\end{array}$ & $\begin{array}{l}\text { conceptual quality is indicated by: } \\
\text { - table of contents, hierarchical maps } \\
\text { - content independent navigation bar or instrument, continuously available site } \\
\text { map or browsing device } \\
\text { - no dead ends and full use of the "return" button }\end{array}$ & $\begin{array}{l}\text { usability } \\
\text { quality of information }\end{array}$ & $\begin{array}{l}2-3 \\
3\end{array}$ \\
\hline \multirow[t]{2}{*}{4.} & user support & „frequently asked questions“ (FAQ), support per e-mail, glossary & usability & 3 \\
\hline & \multicolumn{4}{|l|}{ Accessibility } \\
\hline \multirow[t]{2}{*}{5.} & \multirow[t]{2}{*}{$\begin{array}{l}\text { barrier free } \\
\text { Internet }\end{array}$} & $\begin{array}{l}\text { Refers to the access into a given resource; is the information available } \\
\text { - without special knowledge (web rookies), } \\
\text { - for visually handicapped or blind people } \\
\text { - for very old or pure text browser? } \\
\text { To avoid all unnecessary barriers in scientific resources is a sign of quality. }\end{array}$ & \multirow[t]{2}{*}{$\begin{array}{l}\text { quality of information } \\
\text { usability } \\
\text { quality of the service }\end{array}$} & \multirow[t]{2}{*}{$2-3$} \\
\hline & & $\begin{array}{l}\text { Pages can be checked with }<\text { http://bobby.watchfire.com/bobby/html/en/>, which } \\
\text { provides hints how to modify sites into barrier-free ones. }\end{array}$ & & \\
\hline \multirow[t]{2}{*}{6.} & $\begin{array}{l}\text { access regle- } \\
\text { mentation }\end{array}$ & registration, subscription, payment & usability & 2 \\
\hline & \multicolumn{4}{|c|}{ Formal Structure } \\
\hline \multirow[t]{2}{*}{8.} & $\begin{array}{l}\text { data amount } \\
\text { data structure }\end{array}$ & $\begin{array}{l}\text { Resources should not rely on user's special technical knowledge, conceptual } \\
\text { quality therefore is indicated by: } \\
\text { - formal structure of information is obvious } \\
\text { - users get informed about data amount (high / low resolution) and structure } \\
\text { - complex information is broken down logically }\end{array}$ & $\begin{array}{l}\text { usability } \\
\text { quality of information } \\
\text { quality of the service }\end{array}$ & 3 \\
\hline & $\begin{array}{l}\text { resource } \\
\text { boundaries }\end{array}$ & links should show whether the refer resource-internally or point outside & & \\
\hline 10. & metadata & $\begin{array}{l}\text { scientific resources can gain in quality if complemented with metadata, that: } \\
\text { - clearly marks title and creator } \\
\text { - reveals information about the resource's content and } \\
\text { - allows the retrieval by search-engines and resource-directories by key-words, } \\
\text { descriptions or abstracts }\end{array}$ & $\begin{array}{l}\text { interoperability } \\
\text { quality of the service } \\
\text { usability }\end{array}$ & \\
\hline
\end{tabular}

\section{Technical Features of Resources}

The following criteria refer to the entire technical aspects during the process of resource production and access that turn pure information into a usable media product. Evaluating these features means testing the technical potentials of a given resource in the information chain. They comply to the category "process" of the projects in DESIRE.

\begin{tabular}{|l|l|l|l|l|}
\hline & Term & Description & Meaning and Significance \\
\hline & Usability & \multicolumn{2}{|l|}{} & Priority \\
\hline 1. & data formats & $\begin{array}{l}\text { Conceptual quality is indicated by: } \\
\text { - formats as simple and standardised as possible } \\
\text { - disclosure of down-load and online-session information } \\
\text { - disclosure of add-on modules and use of common standard plug-ins (Acrobat } \\
\text { Reader, Flash, Realplayer, Quicktime etc.) }\end{array}$ & $\begin{array}{l}\text { usability } \\
\text { quality of the service } \\
\text { interoperability }\end{array}$ \\
\hline 2. & $\begin{array}{l}\text { Besides the intellectual indexing metadata refer to technical aspects: } \\
\text { - do they allow interoperability, cataloguing and providing resources? } \\
\text { - do they comply with international and subject-specific standards (for example } \\
\text { DC environment or DC government)? } \\
\text { - support harvesting and OAI }\end{array}$ & $\begin{array}{l}\text { quality of the services } \\
\text { interoperability with other QCSG and } \\
\text { high-quality search engines }\end{array}$ & 4 \\
\hline 3. & $\begin{array}{l}\text { international } \\
\text { standards }\end{array}$ & $\begin{array}{l}\text { Compliance with technical WWW Standards (W3C, ITEE) indicates quality. } \\
\text { Missing technical quality might lead to rejection of otherwise inadequate re- } \\
\text { sources }\end{array}$ & $\begin{array}{l}\text { usability, interoperability } \\
\text { quality of the medium }\end{array}$ \\
\hline
\end{tabular}




\begin{tabular}{|c|c|c|c|c|}
\hline & Term & Description & Meaning and Significance & Priority \\
\hline & \multicolumn{4}{|l|}{ Accessibility } \\
\hline 4. & Reliability & $\begin{array}{l}\text { - Does the providing server run } 24 \text { hours all year long? } \\
\text { - Is the server technically capable and maintained to cope with the provided } \\
\text { resources (latency, access time, waiting time)? } \\
\text { - If advertising is there does it disturb the information access? }\end{array}$ & \begin{tabular}{|l|} 
usability \\
trustworthy source \\
quality of information
\end{tabular} & 2 \\
\hline 5. & Safety & $\begin{array}{l}\text { - Faulty markup language or over-ambitious design might result in problems up } \\
\text { to abnormal system ends. } \\
\text { - cookies, plug ins, registration obligation might be delicate topics for users } \\
\text { - interventions into the user's browser (deactivating the right mouse button), } \\
\text { dubious / exceeding advertising or inadequate pay-modules should be criteria } \\
\text { for down-rating or rejection. }\end{array}$ & $\begin{array}{l}\text { trustworthy source } \\
\text { usability } \\
\text { quality of the service }\end{array}$ & $\begin{array}{ll}2 \\
1-2\end{array}$ \\
\hline & \multicolumn{4}{|l|}{ Interfaces } \\
\hline 6. & $\begin{array}{l}\text { user and } \\
\text { medium }\end{array}$ & $\begin{array}{l}\text { Conceptual quality is indicated by: } \\
\text { - the given resource can be viewed with simple or older browsers as well } \\
\text { - HTML-extensions (Java, JavaScript, ActiveX) or Java-applets have been used } \\
\text { sparingly }\end{array}$ & $\begin{array}{l}\text { precondition for Internet use } \rightarrow \text { see } \\
\text { "barrier freedom" }\end{array}$ & \\
\hline 7. & $\begin{array}{l}\text { inter- and } \\
\text { intramedial } \\
\text { Interfaces }\end{array}$ & $\begin{array}{l}\text { source types like primary data sets gain in quality if they allow easy access for } \\
\text { example for harvesting processes }\end{array}$ & quality of the service & \\
\hline
\end{tabular}

\section{Evaluation as a Relational Process}

To evaluate Internet resources rarely seems to be a linear process during which criteria get tested one after the other but usually in a spiral mode. A certain minimal evaluation for example - subject seems to fall within the scope, contents seem scientific, there is someone like an author and the URL seems reliable - results in the decision to evaluate a given resource in more detail. That might include identifying a source type or relating the resource to deeper levels of the QCSG scope in order to finally accept or reject it for the service. Especially the scope of a QCSG gets related to several parameters and therefore needs to be regarded in different phases of the evaluation process.
Figure 2 shows this staged procedure of:

1. relating the resource's subject to the QCSG's scope

2. identifying the source type

3. evaluating authorship and context

4. evaluating the content according to the source type

\section{Relating Resource's Subject and Scope}

If the resource's subject (which should be defined from a librarian's point of view and therefore rather formal) falls within the QCSG's scope the evaluation can proceed. The "three-click-rule" might be a practical help whereupon after three clicks the subject of a high-quality resource should be obvious.

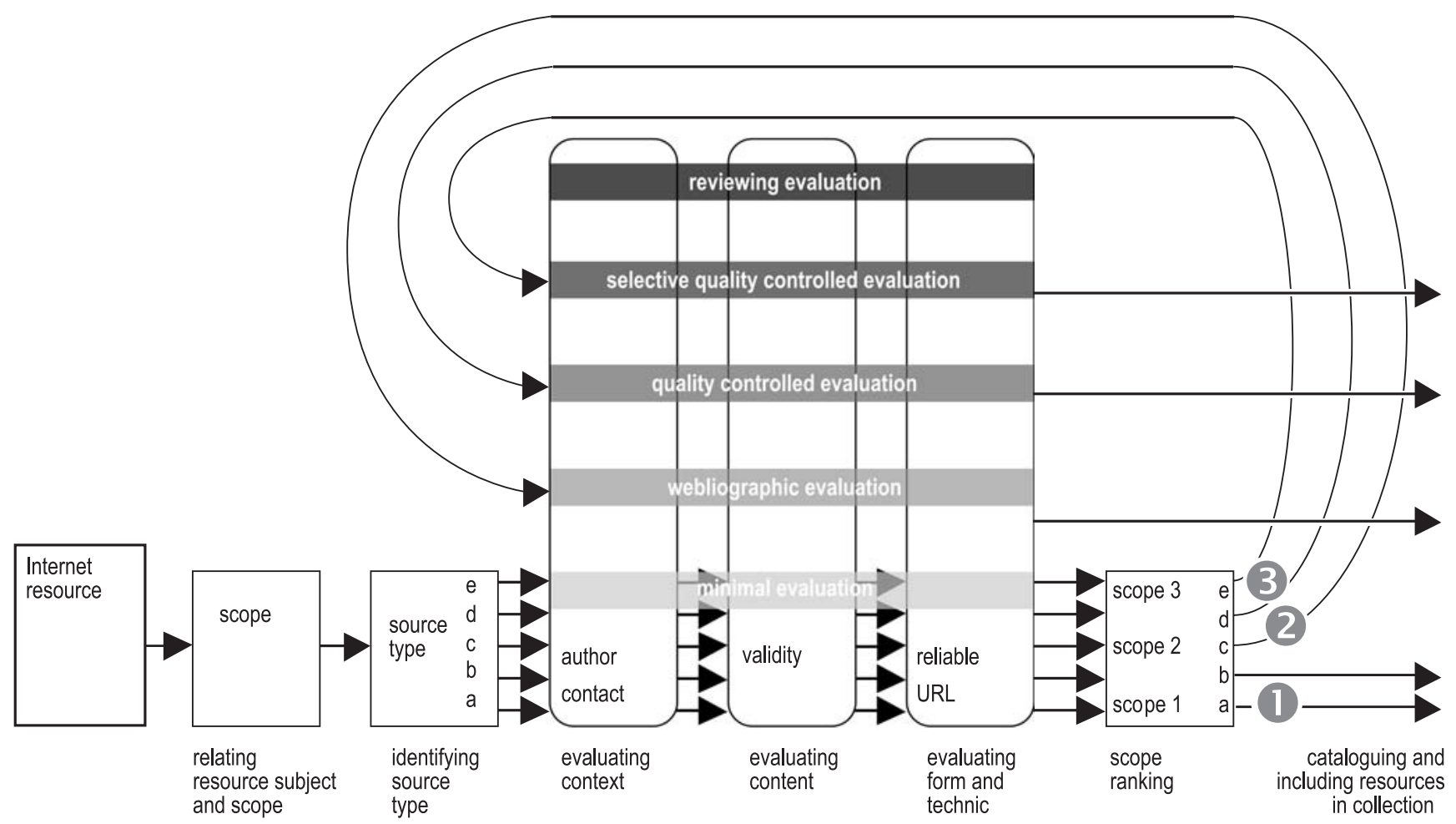

Fig. 2: Staged Procedure of Evaluation 
The scope of a QCSG specifies a certain thematic coverage within a discipline or a certain topic. It can be distinguished according to its orientation towards the target group and towards the collection quality. As there are excellent online resources dealing with the aspect "collection quality" ${ }^{61}$ we focus on the former.

The main objective of an information service such as a QCSG - what kind of information should be provided in which way for whom - can be regarded as "scope policy" or "selection policy". A scope policy should be formulated beforehand in order to provide users a coherent collection of Internet resources. The thematic orientation usually does not change over time but surely needs to be evaluated and modified occasionally. The practical work has shown that QCSG should openly publish their selection policy. On the one hand this might guide the following collection practice, on the other hand it might inform users what kind of service they can expect as well as information providers whether their resources might meet the scope or not. A scope policy therefore can regard the following aspects:

\begin{tabular}{|l|l|}
\hline \multirow{5}{*}{$\begin{array}{l}\text { included } \\
\text { information }\end{array}$} & thematic bias of the information service \\
\cline { 2 - 2 } & $\begin{array}{l}\text { level of the indexed information (strictly scientific or } \\
\text { scientifically relevant?) }\end{array}$ \\
\cline { 2 - 2 } & source types to be indexed \\
\cline { 2 - 2 } contents that usually get rejected \\
\cline { 2 - 2 } $\begin{array}{l}\text { resource } \\
\text { access } \\
\text { that should be represented }\end{array}$ \\
$\begin{array}{l}\text { which technical configuration would users need for the } \\
\text { indexed resources? }\end{array}$ \\
\cline { 2 - 2 } & $\begin{array}{l}\text { which access reglementation (registration, pay-per-view) } \\
\text { would users accept? }\end{array}$ \\
\hline
\end{tabular}

Usually an information service will index the different source types within a given discipline with different aims and intensities to guarantee a broad coverage of the subject. We distinguish three levels of scope. Resources with scope 1 can be accepted after minimal evaluation, whereas scope 2 and 3 resources have to meet other quality criteria as well.

\begin{tabular}{l|l|}
\hline $\begin{array}{l}\text { collection } \\
\text { policy }\end{array}$ & comprehensiveness (as an ideal) \\
\hline $\begin{array}{l}\text { collection } \\
\text { management }\end{array}$ & $\begin{array}{l}\text { comprehensive indexing of subject regarding online } \\
\text { representations (research organisations, academic insti- } \\
\text { tutes, scientific societies, scientific publishers) }\end{array}$ \\
\hline & $\begin{array}{l}\text { comprehensive indexing of subject regarding web-serv- } \\
\text { ices, online journals, news groups etc. }\end{array}$ \\
\hline & $\begin{array}{l}\text { thematically narrow web-services: all adequate re- } \\
\text { sources regarding the subject }\end{array}$
\end{tabular}

\begin{tabular}{l|l|} 
& Scope 2 \\
\hline $\begin{array}{l}\text { collection } \\
\text { policy }\end{array}$ & high-quality collection \\
\hline $\begin{array}{l}\text { collection } \\
\text { management }\end{array}$ & $\begin{array}{l}\text { systematic indexing of high-quality resources within } \\
\text { the QCSG's scope }\end{array}$ \\
\hline & $\begin{array}{l}\text { systematic indexing for underrepresented areas of the } \\
\text { collection; in this case subject-accordance overrides } \\
\text { quality }\end{array}$
\end{tabular}

\begin{tabular}{l|l|} 
& Scope 3 \\
\hline $\begin{array}{l}\text { collection } \\
\text { policy }\end{array}$ & enhancing scope and depth \\
\hline $\begin{array}{l}\text { collection } \\
\text { management }\end{array}$ & $\begin{array}{l}\text { selective indexing to cover all needed subsets of the } \\
\text { subject; subject-accordance overrides quality }\end{array}$ \\
\hline
\end{tabular}

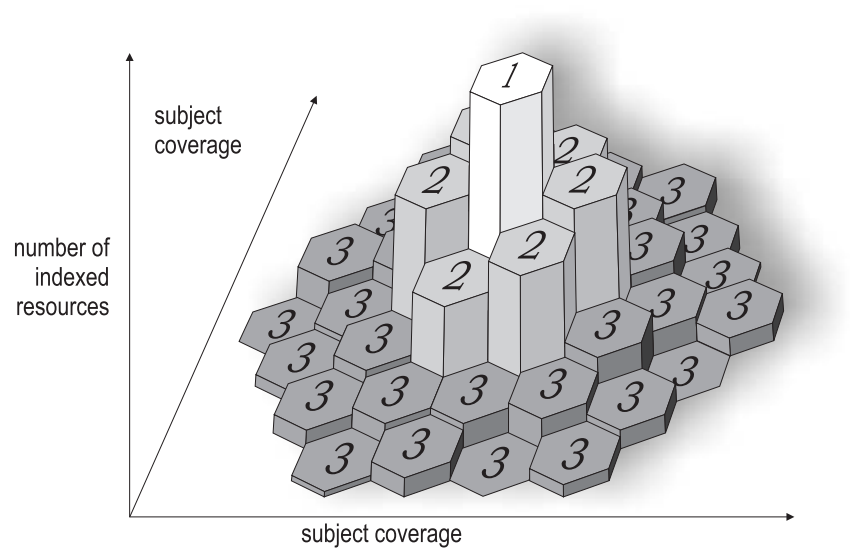

Fig. 3: Quantitative Distribution of Resources Belonging to Scope 1, 2 and 3

\begin{tabular}{|l|l|}
\hline $\begin{array}{l}\text { age to adjacent subjects and disciplines; high-quality } \\
\text { resources might be indexed even with little subject } \\
\text { reference }\end{array}$
\end{tabular}

For visualisation of the scope priorities see figure 3 .

A practical example should clarify this staged procedure. Scientific information services usually can be understood as a subjectspecific virtual "information desk". Our QCSG "Math Guide"62 for the Pure Mathematics started with the objective to index all academic institutions from the German-speaking and Scandinavian area as well as all mathematical societies with German or English homepages.

I.e. these resources were meant to be indexed as much as possible, they belonged to a certain source type (here defined as "institutional sites") and therefore only had to pass a minimal evaluation. In the meantime these categories have been filled sufficiently and the range of indexable resources has grown. This called for a change of collection strategy to differentiate more and less valuable and indexable resources and the evaluation on higher levels. Scope 2 refers to resources that generally meet the service's subject and might contribute to comprehensively cover the subject. Therefore these resources have to meet requirements beyond that of scope 1. If a certain subject area is sufficiently covered only resources of special quality get indexed or might even replace inferior ones.

The category scope 3 refers to resources that deal with marginal

61 The aspects of collection quality and collection management policy refer to coverage and scope as well but focus on the perspective of the providing institution. See the paragraphs "Considering the Service" in DESIRE handbook, section 1 "strategic issues", 2.6 "Collection management" and Louis Pitschmann 2001: paragraphs 4 to 9, <http://www.clir.org/pubs/ reports/pub98/contents.html>

$62<$ http://www.mathguide.de>. 


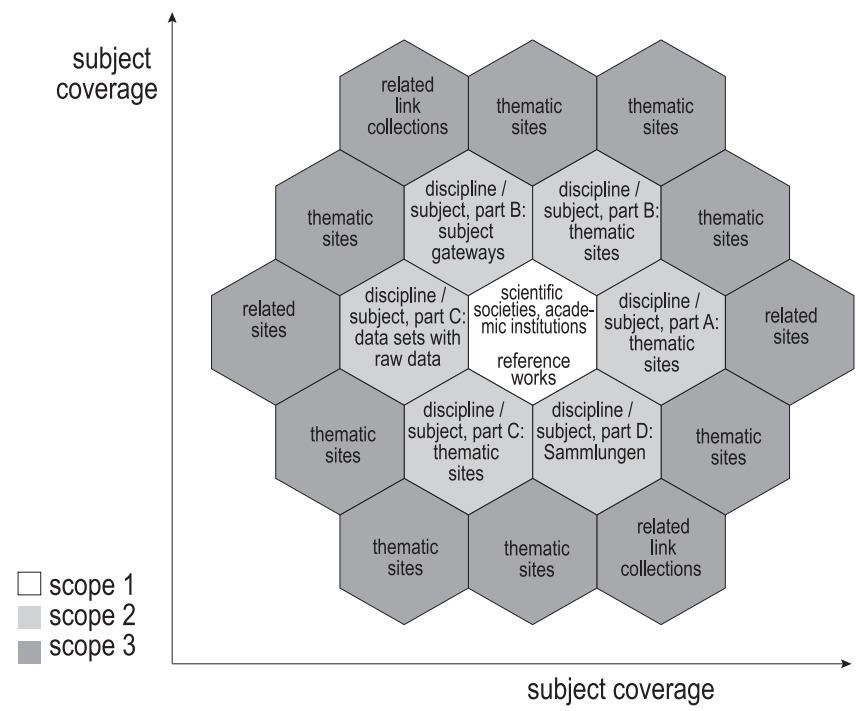

Fig. 4: Qualitative Mode of Distribution. Indexed Resources Covering a Discipline / Subject in Quantitative Mode

aspects of a subject, come from other disciplines but show a subject connection, which belong to an already saturated area of the subject or whose source type only gets indexed in case of special quality (for example link collections).

Identifying the Source Type

To identify a source type follows two objectives: first of all cataloguing resources becomes easier and more user-friendly if the source type is somehow identified. On the other hand evaluation can be more specific as aspects like currency and maintenance have to be regarded differently for archives or calendar of events. For many QCSG it might be useful thus to define the scope in a way that favours certain source types such as institutional homepages, collections or reference works.

We recommend to start the source type schema from the subjectspecific bibliographic schema and modify it according to the Internet's features in alignment with international standards. As an example we show the source types developed by the Dublin Core Metadata Initiative (DCMI) ${ }^{63}$ that mainly refer to data formats.
These source types might serve as a principal classification within the metadata schema to allow international interoperability. From the librarian's point of view though it is useful to refine them according to content- and subject-regarding aspects.

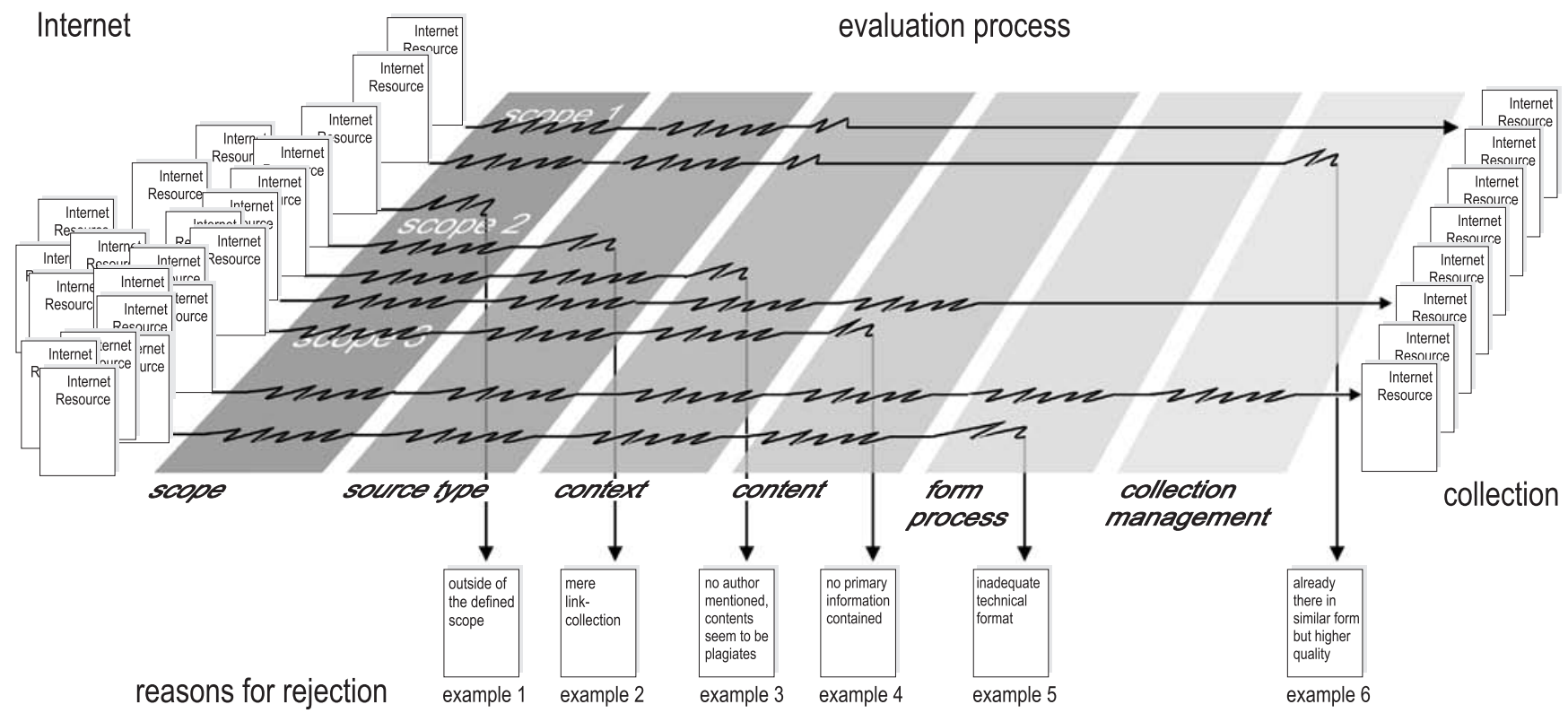

Fig. 5: Relating Scope, Source Type and Content 


\begin{tabular}{|c|c|}
\hline Type & Description \\
\hline Collections & $\begin{array}{l}\text { A collection is an aggregation of items. The term collection } \\
\text { means that the resource is described as a group; its parts may } \\
\text { be separately described and navigated. }\end{array}$ \\
\hline Data-set & $\begin{array}{l}\text { A dataset is information encoded in a defined structure (for } \\
\text { example, lists, tables, and databases), intended to be useful for } \\
\text { direct machine processing. }\end{array}$ \\
\hline Event & $\begin{array}{l}\text { An event is a non-persistent, time-based occurrence. Metadata } \\
\text { for an event provides information as a basis for discovering } \\
\text { purpose, location, duration, responsible agents, and links to } \\
\text { related events and resources. The resource of type event may } \\
\text { not be retrievable if the described instantiation has expired or } \\
\text { is yet to occur. }\end{array}$ \\
\hline Image & $\begin{array}{l}\text { An image is a primarily symbolic visual representation other } \\
\text { than text. For example - images and photographs of physical } \\
\text { objects, paintings, prints, drawings, other images and graphics, } \\
\text { animations and moving pictures, film, diagrams, maps, musi- } \\
\text { cal notation. Note that image may include both electronic and } \\
\text { physical representations. }\end{array}$ \\
\hline $\begin{array}{l}\text { Interactive } \\
\text { Resource }\end{array}$ & $\begin{array}{l}\text { An interactive resource is a resource which requires interaction } \\
\text { from the user to be understood, executed, or experienced. For } \\
\text { example - forms on web pages, applets, multimedia learning } \\
\text { objects, chat services, virtual reality. }\end{array}$ \\
\hline Service & $\begin{array}{l}\text { A service is a system that provides one or more functions of } \\
\text { value to the end-user. Examples include: a banking service, } \\
\text { interlibrary loans, a Z39.50 or Web server. }\end{array}$ \\
\hline Software & $\begin{array}{l}\text { Software is a computer program in source or compiled form } \\
\text { which may be available for installation non-transiently on an- } \\
\text { other machine. }\end{array}$ \\
\hline Sound & $\begin{array}{l}\text { A sound is a resource whose content is primarily intended to be } \\
\text { rendered as audio. }\end{array}$ \\
\hline Text & $\begin{array}{l}\text { A text is a resource whose content is primarily words for read- } \\
\text { ing. For example - books, letters, dissertations, poems, news- } \\
\text { papers, articles, archives of mailing lists. Note that images of } \\
\text { texts are still of the genre text. }\end{array}$ \\
\hline $\begin{array}{l}\text { Physical } \\
\text { Object }\end{array}$ & $\begin{array}{l}\text { An inanimate, three-dimensional object or substance. Note that } \\
\text { digital representations of, or surrogates for, these things should } \\
\text { use Image, Text or one of the other types. }\end{array}$ \\
\hline
\end{tabular}

\section{Relating Scope, Source Type and Content}

The following (fictional) examples should clarify how scope, source type, content and technical features get related to each other; figure 5 illustrates where such resources actually fall out of the evaluation process.

\section{Example 1:}

While researching for an anthropological subject gateway on Papua New Guinea you might find the URL < http://uni-debris.de/ publ/ meyer-suse/abelam.html> that could be scientific as the server is run by a university. When looking into it you realise that it refers to the people called Abelam but only contains a directory of photographs that have been taken during a holiday trip of someone called Meyer. You do not index the resource.

\section{Example 2}

During the same research a resource appears with the title "Indonesia: Bali materials". The promising title refers to a link collection. According to our scope the source type "link collection" should only be indexed when displaying extra quality or special information. The given Bali compilation does not bring any new information and is therefore left aside.

\section{Example 3}

However the found link collection contains a promising site on temple rituals that appears to be scientific although you cannot find an author except an anonymous e-mail address and no references. You copy a sentence from the introduction and let Google search for it: the text has probably been copied from an anthropologist's homepage who is a renowned expert in this field. The resource is rejected.

\section{Example 4}

For a medical QCSG your research takes you to a site on phosphodiesterase-inhibitors published by a pharmacological institute. Such sites usually belong to the margin of your scope and therefore need to be of special quality in order to be indexed. As the site mainly contains reviews of pharmacological studies, i.e. secondary information and you do not yet have the according medical primary information you bookmark it to add it later.

\section{Example 5}

Another resource on phosphodiesterase-inhibitors displays a physician as the author and describes a clinical study, i.e. primary medical information. After evaluating the author as an expert on the topic you look into some of the following HTML-pages whose content seem to be of scientific quality. Due to too-high resolution the included pictures cause down-load problems and the resource displays several dead-ends. The references show that the author has published a shorter version in the renowned Journal JAMA ${ }^{64}$, so you index the more reliable PDF-version instead.

\section{Example 6}

For your QCSG on English authors you come across a new site on Anita Desai which might accomplish the already existing resources in your service. But the new one does not offer any further information and is of no higher quality so you leave it aside.

\section{Conclusion}

Writing on evaluating Internet resources - dynamic objects in a constantly changing medium - will always have an interim character. This refers especially to quality criteria as "quality" stays a relative concept depending on different needs and point of views. Instead of giving long-term solutions the article should rather sharpen the consciousness for the medium Internet and the implications for its media products as well as pointing out existing gaps in the scientific information infrastructure.

The Internet has become crucial for the scientific information and apparently generates new forms of reliable structures such as

\footnotetext{
${ }^{63}$ Current version of the Dublin Core Type Vocabulary (13. Juli 2002).

${ }^{64}$ The Journal of the American Medical Association. <http://jama.amaassn.org/>
} 